\title{
Experimental Pressure Drop and Heat Transfer in a Rectangular Channel with a Sinusoidal Porous Screen
}

\author{
Gazi I. Mahmood ${ }^{1}$ \\ e-mail: Gazi.Mahmood@up.ac.za \\ Carey J. Simonson \\ e-mail: Carey.Simonson@usask.ca
}

Robert W. Besant

e-mail: bob.besant@usask.ca

Mechanical Engineering Department, University of Saskatchewan, Saskatoon S7N 5A9, Canada.

\begin{abstract}
Experiments are conducted to investigate turbulence enhancing effects of a porous mesh-screen with a sinusoidal shape normal to the flow direction inside a rectangular cross-section air channel at low Reynolds numbers (i.e. Re=1360 to 3800). The baseline measurements are obtained at the same channel and Reynolds numbers without the screen present. The surface of the screen pores are oriented parallel to the mean flow. Data are presented for the total and wall-static pressure drop along the channel, Nusselt number distributions on the heated wall at several constant heat rates, and air temperature distributions at the channel exit with and without (baseline cases) the screen. The heat transfer measurements are obtained with one wall heated as well as two parallel walls heated to simulate different applications for air channels in the flat plate heat exchangers. The results indicate that the ratio of screen channel to baseline Nusselt number $\left(\mathrm{Nu} / \mathrm{Nu}_{0}\right)$ and the ratio of screen channel to baseline friction factor $\left(f / f_{0}\right)$ increase with the Reynolds number (Re). The fully developed $\mathrm{Nu} / \mathrm{Nu}$ is $2.0-2.5$ as the fully developed $f / f_{0}$ is 4.4 at $3100<R e \leq 3800$. However, the screen channel heat convection performance index, $(\mathrm{Nu} / \mathrm{Nu})_{0} /\left(f / f_{0}\right)^{1 / 3}$ is only greater than 1.0 when Re 2500 which is the design objective of reducing the pumping power and heat transfer area in the channel. Nonetheless, the screen insert is only beneficial to augment the convective heat transfer in the channel over the range of transition Reynolds number tested. The average total pressure drop across the channel and average exit air temperature suggest that the screen insert promotes good mixing of fluid across the channel for the Reynolds numbers tested.
\end{abstract}

Keywords: Mesh screen, Enhanced heat transfer, Friction factor ratio, Thermal performance.

\section{INTRODUCTION}

Channels inside of heat exchangers are often equipped with elements (e.g., surface roughness, inserts, pin type geometries, and swirl generating devices) to enhance convective heat transfer when

\footnotetext{
${ }^{1}$ Corresponding author. Present address: Mech. and Aero. Engr. Dept., Univ. of Pretoria, South Africa.
} 
the Reynolds number is low [1]. Such elements cause flow instability near the channel walls promoting turbulence in each flow channel. These elements increase the ratio of heat convection area to channel length so they act as fins. At the same flow rate turbulence promoters are accompanied with the higher pressure drops across the heat exchangers compared to the ones without turbulence promoters. Some flat plate heat exchangers and rotary-wheel heat and enthalpy exchangers employ corrugated metal screens between the channels to exchange heat and moisture between streams and to provide the structural support. The potential of employing the corrugated porous screen as a turbulence promoter in the channels of flat plate heat exchangers is numerically investigated by LePoudre et al. [2]. The present experiments investigate the pressure drop and heat transfer in a rectangular channel employing a similar corrugated insert. The insert is a very porous metal mesh screen having a sinusoidal crosssection for the corrugation. Sinusoidal screens are sometimes used for spacing in air channels but are not usually considered as typical bonded internal fins as the contact between the screen and the heat transfer surface is on a line often with poor thermal contact or has a high contact resistance.

Numerous numerical and experimental investigations on flow structure, heat transfer, and pressure drop in channels with different internal wall roughness and fin inserts have been reported in the literature. Augmentation of heat convection over the past 50 years has been summarized by Webb and Kim [1] for fin inserts and wall roughness for flow through tubes and channels with the accompanying pressure penalty. The flow regime in these investigations ranged from laminar to fully turbulent flow. The common causes of convective heat transfer augmentation with increased pressure penalty using internal fins and wall roughness compared to the smooth channel flows are the local increase of temperature and velocity gradients near the wall region caused by non-steady or turbulent secondary flow.

Heat transfer augmentation and accompanying pressure penalty in channels employing the perforated plates and inserts parallel to the mean flow are studied by [3-5]. The flow $R e$ in these investigations ranges from laminar to transition regime. Flow visualization by Fujii et al. [3] in the channel shows the secondary flow induction by the suction and injection through the perforations. The $\mathrm{Nu}$ and $f$ in [3] are dependent on the perforated plate geometry, spacing between the perforated plates, and porosity of the plates along with the Re. The numerical study by Torii et al. [4] indicates early flow transition with perforated flat inserts in the channel augmenting heat transfer compared to the flow between smooth parallel plates. Heat transfer enhancement and corresponding friction factor in a solar panel heater employing flat wire mesh screens are measured in Varshney and Saini [5]. The Colburn Jfactor for heat convection and friction factors for flow are presented in [5]. The results of [5] show dependence on wire screen geometry and porosity, and $R e$.

Numerical models by Kiwan and Al-Nimr [6], and Hamdan and Al-Nimr [7] employ 1-dimensional porous fins periodically between parallel plates to perturb laminar flow. The objectives of the studies are to replace the solid fins with the porous fins that provide similar thermal performance as the solid fins but with the advantage of significant weight reduction for the compact heat exchanger design. The investigations $[6,7]$ show the augmentation of heat transfer and friction factor in a porous finned channel relative to a smooth channel with varying effects from the fin geometry, porosity, and thermal conductivity. Numerical and experimental investigations by Zhang and Chen [8] report the mean $f$ and $\mathrm{Nu}$ across periodic triangular ducts where the walls are solid non-porous. However, no wall separates the two cross-flow streams in [8] allowing interactions between the cross-stream flows. The 
experiments by Liang and Yang [9] employ perforated flat-plate inserts in a channel parallel to the flow for heat transfer augmentation and report improvement in the heat transfer when Re are high.

The purpose of this research is to measure the pressure drop and convective heat transfer in a single rectangular cross-section air flow channel with and without a single mesh screen insert. The sinusoidal screen is placed in the channel such that the sinusoidal wave vector is parallel to the mean flow direction. The screen mesh porosity is high and stiffness of the screen provides structural support to the parallel walls in a flat plate heat exchanger at the screen/wall contact points. The $R e$ varies between 1360 and 3800. Low Reynolds numbers in heat exchanger air channels are favorable to limit the fan power [1]. Measurements are obtained when the convective heat transfer is symmetric (i.e. two parallel walls of the channel are heated) as well as asymmetrical when only one wall is heated with the other walls insulated. Heat exchanger channels with one side heated are typically employed in the solar heater panels, side channels of multi-channel heat exchangers, and electronic chip cooling. The results provide data for the convective heat transfer and pressure penalty (air pumping power) for the screen in channel relative to a smooth channel. The objective of the experiments is to quantify thermal performance in a channel with sinusoidal porous screen compared to one without. Improvement in thermal performance may include: (i) smaller channel surface area for a given heat load and flow rate, (ii) higher heat load for the same channel surface area and flow rate, and (iii) lower fan power or flow rate for the same heat load and channel surface area. The results can aid designers of the flat plate energy exchangers to meet the above design objectives.

\section{EXPERIMENTAL SETUP}

\subsection{Test Channel and Instrumentation}

The measurements are obtained in a test facility with a low speed test section. Ambient laboratory air is drawn into the test section with a blower located at the downstream end of the test facility. Figure 1 (a) shows the schematic of the test facility. As indicated in the figure, the test facility has four main sections of rectangular cross-section: a two-dimensional contraction nozzle (length $320 \mathrm{~mm}$ ), a flow development section (length $2000 \mathrm{~mm}$ ), a test section (length $500 \mathrm{~mm}$ ), and an extension channel (length $150 \mathrm{~mm}$ ). The contraction ratio of the inlet nozzle is $27: 1$ with an exit height of $5.0 \mathrm{~mm}$. The cross-section of the channel parts from the nozzle exit to the end of the extension channel is $5.0 \mathrm{~mm}$ by $152.4 \mathrm{~mm}$ (Fig. 1b). The channel height, $5.0 \mathrm{~mm}$, is based on the design of the air-channel gap in some commercial plate heat-exchangers and the available corrugated air-filter screens employed as spacers in these exchangers. As shown in the Fig. 1(a), ambient air enters the nozzle and then accelerates smoothly before entering the flow development section. The boundary layer and boundary disturbances formed in the nozzle flow are bled out by a small blower through a $3.0 \mathrm{~mm}$ gap between the nozzle exit and inlet of the flow development section. The length of the flow development section then allows a smooth growth of the air-flow boundary layer which becomes fully developed as the air stream enters the test section. The channel walls are made of $12.5 \mathrm{~mm}$ thick commercial acrylic plates. Following the extension channel, air enters into a large exit plenum and then into a PVC pipe of diameter $50.8 \mathrm{~mm}$. The pipe section contains an ISO standard [10] orifice plate that determines the air-mass flow rate. The pipe length is $134 \mathrm{~cm}$ upstream and $75 \mathrm{~cm}$ downstream of the orifice plate exceeding the minimum pipe length required in the ISO 5167-1980 [10]. A commercial vacuum blower located at the pipe outlet as 
shown in Fig. 1(a) draws in air in the channel. The seams between the adjacent channel sections are masked with weather caulks to prevent any air leaks into the channels.

Figure 1(b) indicates the Cartesian coordinate system employed for the measurements. One of the $152.4 \mathrm{~mm}$ wide walls of the test section is fitted with $0.3 \mathrm{~mm}$ drilled static pressure taps along the middle as shown in Fig. 1(b). The thirty-three pressure taps are located $15.0 \mathrm{~mm}$ apart from each other and connected to an electro-mechanical scanner via plastic tubing. The scanner is connected to a DP103 Validyne $^{\mathrm{TM}}$ differential pressure transducer. The scanner connects one pressure port at a time to the pressure transducer when an electrical signal is triggered from a controller. A slot cut-out in a wall of the extension channel downstream of the test section is used for inserting either a total-pressure probe or a temperature probe. This probe can be used to scan the total pressure or air temperature of the air-flow in a YZ-plane, which is normal to the mean exit-flow direction, located about $10 \mathrm{~mm}$ downstream of the test section exit. A two-axis motorized traverse is employed to move the probe for scanning. A weather strip and a pair of overlapping tape-strips are used to cover the slot to minimize air leaks while the probe traverses in the slot.

The $152.4 \mathrm{~mm}$ wide top and bottom walls of the test section are removable and can be replaced with $6.0 \mathrm{~mm}$ thick acrylic plates instrumented with heaters and T-type thermocouples as shown in Fig. 1(c) for the heat transfer measurements. The heaters are built in-house and made of $6.4 \mathrm{~mm}$ wide and 0.07 $\mathrm{mm}$ thick commercial copper strips with an adhesive back. These copper strips are laid in parallel 0.3 $\mathrm{mm}$ apart on the acrylic wall and soldered at the ends in a serpentine pattern to form a continuous heater on the flow side of the wall. The copper strips are covered with $0.06 \mathrm{~mm}$ thick commercial Kapton $^{\mathrm{TM}}$ tape. The Kapton ${ }^{\mathrm{TM}}$ layer is then covered with $0.08 \mathrm{~mm}$ thick copper foil. Thus, the heater arrangement can provide a constant power flux along the test surface with a DC voltage input. The test section walls are insulated with two layers of Styrofoam ${ }^{\mathrm{TM}}$ as shown in Fig. 1(c) during the heat transfer measurements. The thickness of each insulation layer is $23.5 \mathrm{~mm}$. There are also thermocouples located between the insulation layers and between the insulation layer and acrylic wall to measure the heat loss to the ambient.

Figure 2(a) shows the locations of the thermocouple tips or heat transfer measurements along the heated test plate in the test section. There are twenty-seven T-type thermocouples embedded in the $125 \mathrm{~mm}$ of downstream end of the test plate. As shown in Fig. 2(a), the thermocouples are $10 \mathrm{~mm}$ apart from each other in the Y-direction, but are either $15 \mathrm{~mm}$ or $10 \mathrm{~mm}$ apart in the X-direction depending on their distances from the plate trailing edge. The thermocouple tips are inserted through drilled holes in the test plate and placed just below the heater elements (Fig. 2b). The holes are filled in with thermally conductive paste.

\subsection{Air-Screen Geometry}

The screen tested is a commercial corrugated air-filter screen manufactured by Hengrong Metal Mesh Filters Co. Ltd, China [11]. The corrugated shape of the screen is approximately sinusoidal, as shown in Fig. 3, with a period of $12.5 \mathrm{~mm}$ and a peak-to-peak height of $5.0 \mathrm{~mm}$. The +X-direction in Fig. 3 is parallel to the sinusoidal wave vector and mean flow stream. The screen material is stainless steel with a wire diameter of $0.13 \mathrm{~mm}$. The screen pores are diamond-like with the geometry as shown in Fig. $3(b)$. The number of pores is about $14 / \mathrm{cm}^{2}$ of the screen area. Thus, the calculated porosity of the tested screen is about $79.4 \%$. The screen in the test section is laid such that the screen period is normal to the 
bulk flow direction (Fig. 3b) and the screen covers the entire length $(500 \mathrm{~mm})$ and width $(152.4 \mathrm{~mm})$ of the test section. One of the test plates (Fig. 1c) in the test section is removed to place the screen on top of the other test plate without any gluing or soldering. When the plate is put back in place, visual inspection is done to check for the contacts between the peaks of the screen sinusoids and test plates. Because of the stiffness and unevenness in the screen, there are some locations where the screen and test plates might not contact. As the screen insert is to affect the convective heat transfer primarily by promoting the local turbulence mixing, contact points with the heated surface like fins are not important for heat transfer enhancements from the surface. Like bonded fins, the porous screen does not increase the heat transfer surface area.

\section{MEASUREMENT TECHNIQUE}

All measurements are obtained as the flow reaches the steady-state condition which is determined when the pressure and temperature change by less than $2.0 \mathrm{~Pa}$ and $0.1^{\circ} \mathrm{C}$, respectively, over a period of 10 minutes. The air flow is incompressible due to the small velocities tested and pressure drops across the test section. The voltage signals from the pressure transducer and thermocouples are obtained with a National Instrument data acquisition system via a Labview ${ }^{\mathrm{TM}}$ computer program. The data from each acquisition channel are acquired at $500 \mathrm{~Hz}$ for 0.9 seconds for temperature and for 6 seconds for pressure. The voltage signals are then time-averaged and converted into degree Celsius and Pascal after applying the appropriate calibration curves. The static wall pressure difference, $\left(P_{x^{-}} P_{0}\right)$ is normalized relative to the dynamic pressure and reported as a ratio in Eq. (1) where the reference static pressure, $P_{0}$ is measured $10 \mathrm{~mm}$ downstream of the test section inlet.

$$
\Delta P^{*}=\frac{\left(P_{x}-P_{0}\right)}{0.5 \rho_{a} \cdot v_{a}^{2}}
$$

The total-pressure probe has a diameter of $0.30 \mathrm{~mm}$ and scans the $Y Z$-plane $10 \mathrm{~mm}$ downstream of the test section exit with $0.5 \mathrm{~mm}$ by $0.5 \mathrm{~mm}$ spatial resolution. The motorized traverse system used for moving the probe is controlled via the same Labview ${ }^{\mathrm{TM}}$ program that is used for the data acquisition. The measured local total pressure difference, $\left(P_{i n, 0}-P_{e x, 0}\right)$ is normalized in Eq. (2). The inlet total pressure $P_{i n, 0}$ in Eq. (2) is measured $30 \mathrm{~mm}$ upstream of the test section inlet.

$$
\Delta P_{0}^{*}=\frac{\left(P_{i n, 0}-P_{e x, 0}\right)}{0.5 \rho_{a} \cdot v_{a}^{2}}
$$

The air-mass flow rate is measured with the orifice plate located in the pipe section following the exit plenum in Fig. 1(a). The discharge coefficient for the orifice plate at each measured pressure drop across the orifice is determined from the Stolz equation [10] in ISO 5167-1980(E) and through iterations. The air density for mass flow measurements is determined from the ideal gas law at the measured air temperature downstream of the orifice plate. The flow Reynolds number in the channel is then obtained from the mass flow rate and channel hydraulic diameter of $2 \mathrm{H}$. Since the aspect ratio of channel crosssection is small (1:30.5), it provides a hydraulic diameter of $2 H$ the same as that of a two-dimensional parallel plane flow.

For the heat transfer measurements only the top and bottom plates in the test section are heated (Figs. 1b, 1c). Hence, the thermal boundary layer starts as the ambient air enters the heat transfer 
section. The air gaps shown in Fig. 1(c) between the heater element, acrylic plate, and insulation layers are for clarity in the schematic. These air gaps are not present in the physical test setup. As the heater elements are located on the flow side of the plates and the test section walls are insulated, most of the heater power is convected into the air-flow and the conduction losses through the walls are small. The conduction losses through the insulation are measured with the embedded thermocouples in the insulation layers. Based on the one-dimensional conduction analysis, the conduction loss normal to a heated plate is found between 0.70 and 0.80 Watts for all the flow conditions. This amounts to only 2.0\%-5.1\% of the total heater power used on a plate for the tests. To estimate the conduction loss along the heated plate in the flow direction, numerical simulations in the ANSYS-CFX ${ }^{\mathrm{TM}}$ are conducted employing the measured wall temperatures and conduction heat flux normal to the plate. The estimated heat losses are less than 0.01 Watts or less than $0.6 \%$ of the total heater power on a plate in the $X$-direction for all the Reynolds numbers. The analytical models of Maranzana et al. [12] show conductive wall heat transfer in large channels is largely perpendicular to the fluid flow. Axial conduction through the copper-foil layer covering the heater is then assumed negligible. As the measured wall temperature varies little in the $Y$-direction (Fig. 2a), conduction losses are assumed negligible along the heated plate in the $Y$-direction. The heat losses through the unheated insulated walls (the side walls) are then also assumed negligible as the losses through the heated plates are small. The total heater power on a plate is determined from the measured DC current and voltage drop across the heater. The convective power, $Q_{c}$ into the flow from a plate is then calculated subtracting the conduction losses from the total heater power input. The local Nusselt number, $\mathrm{Nu}$ at a thermocouple location is then determined from the average convective heat flux, $Q_{d} /($ L.W) in Eq. (3) and the energy balance as in Eq. (4). The local convective flux can be assumed to differ little from the average flux as the conduction losses through the heated plates and insulation layers are small. The $Q_{c}$ is maintained the same from the two heaters when two walls are heated for a test. The total power, $\Sigma Q_{c, x}$ in Eq. (4) is the total convective power from either two heated plates or one heated plate over the length $X$ in the test section. The thermal conductivity of the air, $k_{a}$ is determined at the local bulk-mean temperature, $T_{m, x}$. A thermocouple located at the test section inlet measures $T_{a, i n}$. A constant value of $C_{p}$ at $T_{a, i n}$ is used for all tests as the air temperature does not rise more than $25^{\circ} \mathrm{C}$ across the test section.

$$
\begin{gathered}
N u=\frac{\left(Q_{c} \cdot D_{h}\right)}{\left[L . W \cdot\left(T_{w, x}-T_{m, x}\right) \cdot k_{a}\right]} \\
T_{m, x}=T_{a, i n}+\frac{\Sigma Q_{c, x}}{\left(M_{a} \cdot C_{p}\right)}
\end{gathered}
$$

During the installation of the thermocouples in the test plates, some might have been dislocated from underneath the heater surface. To correct for the temperature difference between the thermocouple location and corresponding location on the heated surface, an infrared-camera determined surface temperature is measured without any air flow and with one $152.4 \mathrm{~mm}$ wide wall (top wall) of the test section removed (Figs. 1b, 1c). To check for the validity of the corrections for the thermocouple temperatures in the heated walls for different heat flux, the local Nusselt numbers, $\mathrm{Nu}$ are measured and compared for different power flux at the same Reynolds number. The good agreement between the $\mathrm{Nu}$ data confirms that the no-flow corrections for the thermocouple temperatures can be applied for the $\mathrm{Nu}$ measurements at all the flow conditions. To measure and 
compare the heat transfer coefficients along the wall with and without (baseline case) the screen at a given $R e$, heater power is varied to maintain the local wall temperatures about equal at the corresponding locations with and without screen. Thus, the comparative wall boundary condition for the Nusselt number data between the baseline and screen channel at a given $R e$ is the equal wall temperatures. This is required to obtain a value of $\left(T_{w, x}-T_{m, x}\right)$ equal to about $7{ }^{\circ} \mathrm{C}$ to $11{ }^{\circ} \mathrm{C}$ for all test conditions with two heated walls.

The temperature probe is made of 40 gage T-type thermocouple wires and has a tip diameter of 0.30 $\mathrm{mm}$. This probe also scans the $Y Z$-plane $10 \mathrm{~mm}$ downstream of the test section exit with $0.5 \mathrm{~mm}$ by 0.5 $\mathrm{mm}$ spatial resolution. Equation 5 provides the measured local temperature of the exit air stream, $T_{a}$ from the test section normalized by the net convective power from a heated test plate. The temperature, $T_{w}$ in Eq. (5) is the average of wall temperatures from the four thermocouples located at $X / L=0.91$. The variation of $T_{w}$ at the thermocouple locations along $Y$-direction is small with and without screen.

$$
\Delta T_{a}^{*}=\frac{M_{a} \cdot C_{p} \cdot\left(T_{w}-T_{a}\right)}{Q_{c}}
$$

\section{UNCERTAINTY ESTIMATES}

The uncertainties in the measured data are estimated based on the $95 \%$ confidence interval [13] and the errors in the computed values are determined based on the propagation of uncertainty $[14,15]$. The maximum uncertainty in the thermocouple temperature is $0.1{ }^{\circ} \mathrm{C}$. The infrared temperature measurements for $T_{w}$ corrections have the maximum uncertainty of about $0.9{ }^{\circ} \mathrm{C}$. The maximum uncertainty in $Q_{c}$ is 0.10 Watts or $0.3 \%$ of the total heater power on a plate. The uncertainty in $P_{x}$ is 0.8 $P a$ at $R e=1360$ and $1.6 P a$ at $R e=3800$ near the test section downstream side $(X / L>0.9)$. The uncertainty in the measured $P_{e x, 0}$ is $5.8 \%$ of the average total pressure at $R e=1360$ and $2.2 \%$ of the average total pressure at $R e=3800$. The higher uncertainty in $P_{e x, 0}$ at lower $R e$ is caused by the higher uncertainty in the smaller mass flow rate and velocity measurements in the orifice plate. The uncertainty in the mass flow rate measurement is $3.8 \%$ at $R e=1360$ and $1.1 \%$ at $R e=3800$. The calculated $\mathrm{Nu}$ has an uncertainty of $11.5 \%$ at $R e=1360$ and $7.2 \%$ at $R e=3800$ in the baseline smooth test section. The $N u$ uncertainty in the test section with the screen is $14.0 \%$ at $R e=1360$ and $12.5 \%$ at $R e=3800$.

\section{RESULTS And DISCUSSIONS}

Measurements are obtained in the smooth channel (baseline case) with no screen present as well as in the screen channel for the same Reynolds numbers. The data from the baseline case are used as reference for comparison with the screen channel data. The test conditions for all the measurements are summarized in Table 1 . The Re range employed in the tests falls within the transition regime of a smooth channel flow. The flow condition in the screen channel is then most likely transitional for all the $R e$ in Table 1. The heat flux in the table is the estimated average convective heat flux from a heated wall as indicated in Eq. (3) and varies between $202.0 \mathrm{~W} / \mathrm{m}^{2}$ and $364.0 \mathrm{~W} / \mathrm{m}^{2}$ for the baseline tests and between $184.0 \mathrm{~W} / \mathrm{m}^{2}$ and $575.0 \mathrm{~W} / \mathrm{m}^{2}$ for the tests with screen. The flow becomes hydrodynamically 
fully developed in the $2.0 \mathrm{~m}$ long flow development section upstream of the test section for all the $R e$ tested. The channel walls are unheated and isothermal for the pressure measurements in both the baseline and screen channels. Heat transfer measurements are obtained with two walls heated as well as with one wall heated (152.4 $\mathrm{mm}$ plate in the test section). Measured $\mathrm{Nu}$ is then reported on the heated wall at locations of the thermocouples (Fig. 2a).

\subsection{Pressure Drop and Friction Factor}

Figure $4(\mathrm{a})$ shows the normalized $\Delta P^{*}$ in the $X / L$ direction for $R e=1670$ and 3120 with and without screen in the test section. The baseline pressure data in the figure are also obtained from measurements. The $\Delta P^{*}$ data in the figure are determined from Eq. (1). As indicated in Fig. 4(a), the difference $\Delta P^{*}$ drops along $X / L$ as expected for both the baseline and screen channel. Note that higher the negative value or drop for $\Delta P^{*}$ the higher the pressure difference or drop is along the channel. The drop in $\Delta P^{*}$ also increases as $R e$ decreases from 3120 to 1670 with and without screen. The baseline $\Delta P^{*}$ drops linearly along $X / L$ with a constant slope at a $R e_{0}$ for $X / L \geq 0.0$ indicating a fully developed hydrodynamic flow at the beginning of the baseline test section. The line fit to the baseline $\Delta P^{*}$ data in Fig. 4(a) using the linear regression analysis in a spreadsheet program provides values of -2.98 and -1.73 for the constant slope for $R e_{0}=1670$ and 3120, respectively. The corresponding analytical value for laminar flow (Poiseuille flow) between $5.0 \mathrm{~mm}$ apart parallel planes [16] at $R e_{0}=1670$ is also -2.98 .

However, for the tests with screen in Fig. $4(a)$, the slope of $\Delta P^{*}$ with $X / L$ increases in the range of $0.0<X / L<0.35$ and then becomes constant for $X / L>0.35$ which is also shown in the numerical data of [2] for a similar screen channel. The smooth inlet flow into the screen test section undergoes transition in $0<X / L<0.35$ before it becomes fully turbulent near $X / L=0.35$. The turbulent mean velocity profile then becomes fully developed for $X / L>0.35$ and results in a constant slope of $\Delta P^{*}$ along $X / L$ in the screen channel at a $R e$. The developing length, $X / L$ of the turbulent velocity profile is 0.31 and 0.34 for $R e=1670$ and 3120, respectively, in the screen channel implying the entry length for turbulent velocity profile increases with $R e$. Note that the drop and slope of $\Delta P^{*}$ along $X / L$ in Fig. 4(a) are always higher for the screen channel than for the baseline channel at the corresponding $R e$ as expected.

The $f$ in the channel is determined from the slope of the line fit using linear regression on the pressure drop data in the fully developed flow region for all Re tested. The ratio of the friction factor in screen channel to the friction factor in baseline channel, $f / f_{0}$ is plotted in Fig. $4(\mathrm{~b})$ as Re varies. In the plot, Screen/Baseline data refer to the ratio of screen to baseline measured data for a given $R e$ and Screen/Analytic data to the ratio of measured screen data to analytical data for $R e \leq 1670$ from the Poiseuille flow in [16]. The data in Fig. 4(b) then indicate the requirement of increased fluid pumping power in the screen channel as a function of Re. As shown in Fig. 4(b), the comparison of $f / f_{0}$ values for $R e \leq 1670$ between the Screen/Baseline and Screen/Analytic is very good. The Screen/Baseline measured $f / f_{o}$ values increase for $R e \leq 2700$, but decrease for $R e>3000$. At higher flow velocities this behavior of $f / f_{0}$ with $R e$ can be expected for the channel turbulators [17] as the flow becomes more turbulent in the channel with and without screen. The error bars in Fig. 4(b) indicate the uncertainty limits in the measured data. Figure $4(\mathrm{~b})$ also includes some experimental $f / f_{0}$ in a channel $(5.0 \mathrm{~mm}$ height) with perforated plate fins obtained from Kays and London [18]. The $f$ [18] is based on the mean surface shear stress in the channel with a plate fin porosity of $16 \%$ and fin pitch of $1.82 \mathrm{~mm}$. The baseline $f_{0}$ in Fin 
[18]/Baseline data are obtained from the present baseline measurements without screen. The measured $f$ in the present screen channel incorporates pressure drop caused by both the shear stress and form drag. The $f$-Re relationship in the screen channel can be given by a simple correlation, $f=10.141(R e)^{-0.687}$ for $1360 \leq R e \leq 3800$ tested. The ratio $f / f_{0}$ is then related to $R e$ by the correlations, $\left(f / f_{0}\right)=0.027(R e)^{0.681}$ for $1360 \leq R e \leq 2200$ and $\left(f / f_{0}\right)=56.826(R e)^{-0.313}$ for $2200 \leq R e \leq 3800$. All the three correlations predict $f$ and $f / f_{0}$ in the screen channel within $\pm 7 \%$ of the experimental values.

Figure 5(a) presents the contour of normalized $\Delta P_{0}^{*}$ determined from Eq. (2) at $R e=1670$ in a pitchwise plane at $X / L=1.02$. Data are not shown at $Z / H>0.77$ as the construction of the pitot-probe does not allow any measurements in this region. The approximate location of the screen sinusoids upstream of the measurement locations are superposed as the dotted lines in the figure. The legend at top of Fig. 5(a) indicates the contour values of $\Delta P_{0}^{*}$ distributions. The measurement covers about four periods of the screen. The mean flow is directed out of the plane of paper, and channel bottom and top walls are located at $Z / H=0.0$ and 1.0, respectively. The higher the contour values of $\Delta P_{0}^{*}$ are in Fig. 5(a), the higher the total pressure drop across the screen channel. The $\Delta P_{0}^{*}$ distributions, specially the lower $\Delta P_{0}^{*}$ contour values in the channel core region, are periodic along $Y / W$ direction clearly showing the wake periodicity with the period of screen geometry downstream of the screen. In a smooth channel, the $\Delta P_{0}^{*}$ distributions in the same locations as in Fig. 5(a) would have shown uniform values in the pitchwise, $Y / W$ direction and decreased uniformly from the wall region of $Z / H=0$ and 1 to $Z / H=0.5$ because of the boundary layer. As evidenced clearly in Fig. 5(a), the $\Delta P_{0}^{*}$ distributions are not uniform in $Y / W$ direction and decrease non-uniformly from the wall region to the channel core region. The secondary flows due to the screen redistribute the boundary layer and enhance mixing between the wall region and channel core region causing this non-uniformity in the local $\Delta P_{0}^{*}$ distributions. The enhanced mixing affects the convective heat transfer significantly from the heated walls in the screen channel as will be presented later.

The pitch-averaged $\Delta P_{0}^{*}$ distributions along the height of the channel $(Z / H)$ are presented in Fig. 5(b). The pitch-averaged $\Delta P_{0}^{*}$ values are determined from the arithmetic average of the local $\Delta P_{0}^{*}$ data measured at different heights $(Z / H)$ in the channel such as those presented in Fig. 5(a). The average $\Delta P_{0}^{*}$ distributions in Fig. 5(b) are plotted for $R e=1670-3800$ along with the uncertainty limits. The $\Delta P_{0}^{*}$ distribution in Fig. 5(b) for any $R e$ tested decreases by $8.0 \%-9.0 \%$ from $Z / H=0.05$ to $Z / H=0.5$. In the baseline channel, $\Delta P_{0}^{*}$ would have increased by $96 \%$ from $\mathrm{Z} / \mathrm{H}=0.05$ to $\mathrm{Z} / \mathrm{H}=0.5$ which is estimated based on the fully developed velocity profile and data in Fig. 4(a) for Re<2200. This also indicates a good mixing flow between the wall region and channel core region with the screen insert. The average $\Delta P_{0}^{*}$ distributions along $\mathrm{Z} / \mathrm{H}$ decrease as the Reynolds number increases in Fig. $5(\mathrm{~b})$. This occurs as the dynamic pressure $\left(0.5 \rho_{a} \cdot V_{a}^{2}\right)$ in Eq. (2) increases more than the pressure drop $\left(P_{i n, 0}-P_{e x, 0}\right)$ increases with $R e$. The data in Fig. 5 (b) can provide the total fan power required to move air through the channel with the screen insert at a given $R e$ between 1600 and 3800. The average $\Delta P_{0}^{*}$ distribution at a $R e$ is 
expected to be symmetric about $Z / H=0.5$. However, the values of average $\Delta P_{0}^{*}$ near $Z / H=0.0$ in Fig. $5(b)$ are slightly higher than expected because of some flow-blockage effects due to the probe proximity near the wall. Also, the average $\Delta P_{0}^{*}$ values are slightly smaller than expected at $Z / H>0.5$ because of small air leakages from outside through small gaps between the probe stem and slot sealing on the top wall through which the probe is traversed.

\subsection{Nusselt Number with Two Wall Heating}

Figure $6(\mathrm{a})$ and $6(\mathrm{~b})$ provide the local $N u$ and $N u / N u_{0}$ along the length of the channel at the centerline $(Y / W=0.5)$ of the heated wall in the screen channel as Re varies. The data are measured with top and bottom walls heated. The magnitude of heat flux is increased with $R e$ to maintain a reasonable temperature difference between the wall and bulk air flow. The differences $\left(T_{w, x}-T_{m, x}\right)$ in Eq. (3) for $N u_{0}$ are between $9.0{ }^{\circ} \mathrm{C}$ and $11.0{ }^{\circ} \mathrm{C}$ in the baseline channel and between $7.0{ }^{\circ} \mathrm{C}$ and $9.0{ }^{\circ} \mathrm{C}$ for $\mathrm{Nu}$ in the channel with screen depending on the Re. The first location of the data in Fig. $6(\mathrm{a})$ and $6(\mathrm{~b})$ is $X / L=0.75$ as the heat transfer measurements are obtained in the downstream last quarter of the heated wall (Fig. 2a). As shown, the streamwise $N u$ distribution in Fig. 6(a) at a Re changes little in the $X / L$ direction indicating a thermally fully developed flow in the measurement locations. Nusselt number increases with $R e$ which is expected due to the screen generated turbulence. The data in Fig. 6(a) are normalized by the measured baseline $N u_{0}$ at corresponding locations and Re and presented in Fig. 6(b). The measurements for $\mathrm{Nu}$ are also obtained with two heated walls providing uniform heat flux at a given $\mathrm{Re}$. The ratio $\mathrm{Nu} / \mathrm{Nu}_{0}$ indicates the enhancement of heat transfer or convection coefficients due to the screen in the channel when the temperature difference between the wall and bulk flow is the same for the baseline and screen channel. The numerical $\mathrm{Nu} / \mathrm{Nu}_{0}$ ratios ("----Num." symbol) at $R e=1670$ in Fig. 6(b) are obtained by normalizing the measured $\mathrm{Nu}$ data (screen) with the numerical $\mathrm{Nu}$ o for the flow between two heated parallel plates [19]. The agreement at $R e=1670$ between the experimental $N u / N u_{0}$ ratios and experimental/numerical, $\mathrm{Nu} / \mathrm{Nu}$ o ratios is seen to be very good. This also validates the test assumption that the axial conduction through the wall copper-layer adjacent to the air flow is negligible. Similar to the local $\mathrm{Nu}$ data in Fig. $6(\mathrm{a})$, the local $\mathrm{Nu} / N u_{0}$ distribution along the $X / L$ direction at a constant Re in Fig. 6 (b) is also constant as the $N u_{0}$ at these $X / L$ locations reach the fully developed values in the baseline channel. The local $\mathrm{Nu} / \mathrm{Nu}_{0}$ ratios then increase with the $R e$ and are always greater than 1.0 due to the screen promoted enhanced mixing of fluid between the wall region and channel core.

The streamwise-averaged $\mathrm{Nu} / \mathrm{Nu}_{0}$ data in the screen channel along the pitchwise $\mathrm{Y} / W$ direction are shown in Fig. 6(c) for $R e=1360-3800$ with two heated walls. The $\mathrm{Nu} / \mathrm{Nu} \mathrm{u}_{0}$ at a $\mathrm{Re}$ in Fig. 6(c) are obtained by averaging the local $N u / N u_{0}$ values along $X / L$ at constant pitchwise $Y / W$ locations. The $R e^{\prime}$ s for the data are the same as those in Fig. 6(b). The four rows of thermocouples in the pitchwise direction (Fig. 2a) provide four average $\mathrm{Nu} / \mathrm{Nu}$ o data points along $Y / W$ in Fig. $6(\mathrm{c})$. The distributions in Fig. $6(\mathrm{c})$ then illustrate any pitchwise variations of the average $\mathrm{Nu} / \mathrm{Nu}_{0}$ in the screen channel. As shown in the figure, $\mathrm{Nu} / \mathrm{Nu}$ o distribution along $\mathrm{Y} / W$ at a $R e$ is almost constant, but increases with $R e$ as expected. The thermocouples are located $10 \mathrm{~mm}$ apart from each other in the $Y / W$ direction and the screen pitch is $12.5 \mathrm{~mm}$. The superposed dotted lines in Fig. 6(c) indicate the locations of screen sinusoids in the pitchwise $Y / W$ direction. When the pitchwise locations of the thermocouples are virtually considered in 
the locations in a single period of the screen, the locations cover only a small fraction of the period. One should not, therefore, conclude from the distributions in Fig. 6(c) that the pitchwise variations of local $\mathrm{Nu} / \mathrm{Nu}_{0}$ are negligible.

All the local $\mathrm{Nu}$ values at a $\mathrm{Re}$ with two heated walls are arithmetically averaged and presented in Fig. $6(\mathrm{~d})$ as Re varies in the screen channel. The average $N u$ values in Fig. 6(d) can be considered as the fully developed $\mathrm{Nu}$ in the screen channel for the Re's tested. The Fin [18] $\mathrm{Nu}$ data ( $\Delta$ symbol) in Fig. 6(d) are obtained from Kays and London [18] for the same perforated plate fins as in Fig. 4(b) in a $5.0 \mathrm{~mm}$ wide channel. As shown in Fig. 6(d), the $N u$ distributions with Re for both the screen channel and Fin [18] channel are about the same within the uncertainty bounds. The figure indicates that global $\mathrm{Nu}$ value in the screen channel increases by $40 \%$ as Re increases from 1360 to 2200 . However, the global $\mathrm{Nu}$ value for the screen nearly doubles as Re increases from 2200 to 3800 in the transition flow range. When the screen data in Fig. $6(\mathrm{~d})$ are calculated as $\left(0.71^{-0.33} \mathrm{Nu} / \mathrm{Re}\right)$ with 0.71 as the Prandtl number, the calculated data become highly non-linear with $R e$ indicating the transition flow regime for $1360 \leq$ Re $\leq 3800$ [1].

Figure $6(\mathrm{e})$ and $6(\mathrm{f})$ present globally-averaged $\mathrm{Nu} / \mathrm{Nu} u_{0}$ ratios as functions of $R e$ and $f / f_{0}$, respectively, when two walls are heated in the screen channel. The global-average $N u / N u_{0}$ value at a $R e$ is determined by averaging the local $\mathrm{Nu}$ and $\mathrm{Nu}$ o values at all the thermocouple locations at the same $R e$. The Fin [18]/Baseline data in Fig. 6(e) are the ratios of perforated-fin $\mathrm{Nu}$ [18] from Fig. 6(d) to measured average baseline $\mathrm{Nu}_{0}$ in the present smooth channel. As shown in Fig. $6(\mathrm{e})$, average $\mathrm{Nu} / \mathrm{Nu}$ o values with the screen increase by $30 \%\left(\mathrm{Nu} / \mathrm{Nu}_{0}=1.12\right.$ to 1.46$)$ as $R e$ increases from 1360 to 2200 and by $74 \%$ $\left(\mathrm{Nu} / \mathrm{Nu}_{0}=1.46\right.$ to 2.54$)$ as $R e$ increases from 2200 to 3800 in the transition flow range. As expected, the average $\mathrm{Nu} / \mathrm{Nu}_{0}$ distribution implying the heat transfer enhancements with $R e$ in the screen channel relative to the smooth channel is different from the increase in average $N u$ with $R e$ in Fig. $6(\mathrm{~d})$. The same globally-averaged $\mathrm{Nu} / \mathrm{Nu}_{0}$ ratios with the screen as in Fig. 6(e) are plotted for different $f / f_{0}$ in Fig. $6(\mathrm{f})$. The ratios $f / f_{0}$ are the same as those in Fig. 4(b). At any coordinate of Fig. $6(f)$, the Re is the same for both $\mathrm{Nu} / \mathrm{Nu} u_{0}$ and $f / f_{0}$ and is indicated on top axis of Fig. 6(f). As shown in the figure, the global $\mathrm{Nu} / \mathrm{Nu} \mathrm{u}_{0}$ values increase with $f / f_{0}$ for $f / f_{0}<4.40$ and then decrease for higher $f / f_{0}$. This signifies that simply increasing the roughness or friction of the screen may not affect heat transfer enhancement as expected in the channel. Norris correlation in [20] for roughened tube surfaces suggests that $\mathrm{Nu} / \mathrm{Nu}$ o no longer increases as the skin friction ratio of roughened tube to smooth tube becomes higher than 4.0. However, the Norris correlation from [20] is not included in Fig. 6(f) as the flow is assumed fully turbulent as it enters the roughened tube. The fully developed highest $\mathrm{Nu} / \mathrm{Nu}$ o values in the screen channel are thus obtained when $f / f_{0}$ is about 4.40 at $R e>3100$, but not at $f / f_{0}$ of about 5.10 at $2200 \leq R e \leq 2700$. According to [20] as $f / f_{0}$ becomes large, $N u / N u_{0}$ becomes primarily dominated by the conduction resistance of the fluid in and around the screen pores rather being influenced by turbulence mixing. This implies if the screen channel is to operate at a significantly improved thermal performance, the $R e$ must be higher than the laminar range (i.e. Re>3100) so that $f / f_{0}$ reduces for higher $\mathrm{Nu} / \mathrm{Nu}$. The heat transfer enhancement then compensates for the increased pumping power [21]. 


\subsection{Nusselt Number with One Wall Heating}

Figures $7(\mathrm{a})$ to $7(\mathrm{f})$ present the $\mathrm{Nu}$ variations at the wall thermocouple locations in the screen channel when only one wall is heated. The local baseline $N u_{0}$ values used to normalize the $N u$ values in the figures are also measured with one wall heated. The difference, $\left(T_{w, x^{-}} T_{m, x}\right)$ in Eq. (3) for one heated wall is between $13.0{ }^{\circ} \mathrm{C}$ and $17.0{ }^{\circ} \mathrm{C}$ in the baseline channel and between $10.0{ }^{\circ} \mathrm{C}$ and $13.0{ }^{\circ} \mathrm{C}$ in the screen channel depending on the Re. The local $\mathrm{Nu}$ distributions in Fig. 7(a) and the normalized local $\mathrm{Nu} / \mathrm{Nu}_{0}$ distributions in Fig. 7 (b) are shown along the $X / L$ locations at pitchwise $Y / W=0.5$ as the $R$ varies. In both figures, the variations of $\mathrm{Nu}$ or $\mathrm{Nu} / \mathrm{Nu}_{0}$ distributions along $X / L$ are negligible, but increase with the $R e$. This indicates the flow is thermally fully developed in the measurement locations for the $R e^{\prime} \mathrm{s}$ tested in both the baseline and screen channel. Similar observations were made previously (Figs. 6a-6b) when two of the channel walls were heated. The experimental/numerical, $\mathrm{Nu} / \mathrm{Nu}$ o ratios for $R e=1670$ shown as a dotted line ("Num." data) in Fig. 7(b) are plotted when the measured local Nu values in screen channel are normalized by the numerical $\mathrm{Nu}_{0}$ values from [19] for the flow between two parallel plates with one plate heated. The numerical data in [19] provide developing $N u_{0}$ values in the region of $0.70 \leq X / L \leq 1.0$ causing the discrepancy between the measured ( $\Delta$ symbol) and numerical ("----Num." symbol) $\mathrm{Nu} / \mathrm{Nu}$ o distributions in Fig. 7(b).

The streamwise-averaged $\mathrm{Nu} / \mathrm{Nu}$ o distributions in the pitchwise direction, $Y / W$ are shown for different Re in Fig. 7(c). As mentioned, the data are measured with one heated wall in the screen channel and the baseline channel. As shown in Fig. 7(c), the average $\mathrm{Nu} / \mathrm{Nu}$ o distribution increases with $R e$, but remains uniform along $Y / W$ at a $R e$ implying negligible heat transfer in the heated plate along the pitchwise direction. Figure 7 (d) presents the globally-averaged $\mathrm{Nu}$, average of all the measured local $\mathrm{Nu}$ values with one heated wall at a $R e$, as the Re varies in the screen channel. Average $\mathrm{Nu}$ increases with Re in Fig. 7(d) differently than that in Fig. 6(d) with two heated walls. The distribution of average $\mathrm{Nu}$ in $1300 \leq R e \leq 2200$ is about the same in Figs. 6(d) and 7(d), but is higher in $2700 \leq R e \leq 3800$ for Fig. 6(d) data than for Fig. 7(d) data.

The globally-averaged $\mathrm{Nu} / \mathrm{Nu} \mathrm{u}_{0}$ increases by about $49 \%\left(\mathrm{Nu} / \mathrm{Nu} u_{0}=1.36\right.$ to 2.03$)$ in Fig. $7(\mathrm{e})$ as the $R e$ changes between 1360 and 3800 . The same global-average $N u / N u_{0}$ ratios are plotted in Fig. $7(f)$ as dependent upon $f / f_{0}$ ratios with $R e$ being the same for both the ratios. The average $\mathrm{Nu} / \mathrm{Nu}_{0}$ ratios increase with $f / f_{0}$ ratios, but the distributions are different in Fig. 6(f) and Fig. 7(f). It is worth mentioning here again that the applications of screen channel with one heated wall are different from those with two heated walls. One should not, therefore, justify the use of the data in the screen channel for two heated walls over one heated wall, or vice versa.

\subsection{Thermal Performance}

The screen channel performance index in Fig. 8 is computed from the data in Figs. 6(f) and 7(f). The forms of the performance index are suggested by [21,22] to correlate three basic design objectives of the heat exchanger with turbulent inserts relative to a smooth channel heat exchanger. The three objectives are: (i) reduced heat transfer area for equal pumping power and heat transfer rate, (ii) enhanced heat transfer rate for equal pumping power and heat transfer area, and (iii) reduced pumping power for equal heat transfer rate and area. The index, $\left(\mathrm{Nu} / \mathrm{Nu} u_{0}\right) /\left(f / f_{0}\right)^{(1 / 3)}$ in Fig. 8(a) increases with Re for both cases of one heated wall and two heated walls. For the case of two heated walls, 
$\left(\mathrm{Nu} / \mathrm{Nu} u_{0}\right) /\left(f / f_{0}\right)^{(1 / 3)}$ increases by $17 \%$ in the flow range of $1360 \leq R e \leq 2200$ and by $50 \%$ in the flow range of $2700 \leq R e \leq 3800$. In the same range of transition flow for the case of one heated wall, $\left(\mathrm{Nu} / \mathrm{Nu} u_{0}\right) /\left(f / \mathrm{f}_{0}\right)^{(1 / 3)}$ increases by $17 \%$ and $11 \%$, respectively. Any coordinate in Fig. $8(\mathrm{a})$, for example $\left(\mathrm{Nu} / \mathrm{Nu} u_{0}\right) /\left(f / f_{0}\right)^{(1 / 3)}=0.85$ at $R e=2200$ for two heated walls, can then be interpreted in terms of the three design objectives as follows.

(i) Increase screen channel heat transfer area by $\left(1-0.85^{1.5}\right)$ or $22 \%$ when pumping power and heat transfer rate are the same in the screen channel and baseline channel [21, 22].

(ii) Decrease screen channel heat conductance or heat transfer rate by $(1-0.85)$ or $15 \%$ when pumping power and heat transfer area are equal in the screen channel and baseline channel [21, 22].

(iii) Increase screen channel pumping power by $\left(1-0.85^{3.0}\right.$ ) or $39 \%$ when heat transfer rate and heat transfer area are the same in the screen channel and baseline channel [21, 22].

The $\left.(\mathrm{Nu} / \mathrm{Nu})_{0}\right) /\left(f / f_{0}\right)^{(1 / 3)}$ data with one heated wall in Fig. 8(a) can be interpreted similarly in terms of the design objectives above. For a good thermal performance of the screen channel, the applications thus are advantageous when $\left(\mathrm{Nu} / \mathrm{Nu} u_{0}\right) /\left(f / f_{0}\right)^{(1 / 3)}>1.0$ at $R e>2700$ with two heated wall and at $R e>2000$ with one heated wall. The data in Fig. 8(a) can be predicted by the correlations, $\left(\mathrm{Nu} / \mathrm{Nu} u_{0}\right)=0.003(\mathrm{Re})^{0.75}\left(f / f_{0}\right)^{0.33}$ for two heated walls and $\left(\mathrm{Nu} / \mathrm{Nu} u_{0}\right)=0.082(\mathrm{Re})^{0.33}\left(f / f_{0}\right)^{0.33}$ for one heated wall within $\pm 10 \%$ of accuracy.

The performance index, $(\mathrm{Nu} / \mathrm{Nu}) /\left(\mathrm{f} / \mathrm{f}_{0}\right)$ presented in Fig. $8(\mathrm{~b})$ illustrates the enhancement of the heat transfer rate per unit enhancement of the pumping power in the screen channel relative to a heat exchanger with smooth channel for (i) equal temperature difference between the wall and mean flow, and (ii) equal heat transfer surface area. As shown, the index, $\left(N u / N u_{0}\right) /\left(f / f_{0}\right)$ changes little in $1300 \leq R e \leq 2700$ for both the cases of two heated walls and one heated wall. The index then increases with the Re for both cases. The performance index for other types of channel flow turbulators such as ribs [17], pin-fins, winglets, and wavy walls in the literature are provided at Re>5000. Fibrous heat dissipater medium with very high porosity such as the aluminum fibrous block in [23] provides very high heat transfer rate, but the pressure drop through the medium is expected to be very high as well [1] because of the flow blockage.

Figure 9 shows the average normalized $\Delta T_{a}^{*}$ along the height, $Z / H$ direction measured in the pitchwise plane located $10 \mathrm{~mm}$ downstream of the screen channel exit and baseline channel exit when the two walls are heated. This is the same plane as in Fig. 5(a). The data in Fig. 9 are presented for Re of 1670 and 3800 in both channels. The average data in the plot are computed by averaging the local $\Delta T_{a}^{*}$ values at constant $Z / H$ locations. The local $\Delta T_{a}^{*}$ values are calculated using the Eq. (5) from the measured air temperature in the $Y Z$-exit plane. The higher the average values of $\Delta T_{a}^{*}$, the higher the temperature difference between the wall region and measurement location. The local air temperature, $T_{a}$ distributions in the baseline channel are expected to be uniform in the $Y / W$ direction and decrease uniformly from the wall region to the channel core region because of the uniform boundary layer distributions. Such distributions in the baseline channel are then responsible for the parabolic $\Delta T_{a}^{*}$ distributions in Fig. 9 with the highest value near $Z / H=0.5$ and the lowest values near the bottom heated wall $(Z / H=0.16)$ and top heated wall $(Z / H=0.80)$. Compared to the baseline data, the average 
$\Delta T_{a}^{*}$ distributions in the screen channel are lower and more uniform in the $Z / H$ direction due to the turbulent mixing, secondary flows and enhanced convection. The screen insert thus can provide a desirable uniform temperature distribution along the channel depth in a heat exchanger.

Using the temperature profile data from Fig. 9, the exit air bulk-mean temperature is calculated and compared with the estimated $T_{m, x}$ from Eq. (4) at $X / L=1.0$ to check on the energy balance in the channel with and without screen. The exit flow velocity profile is estimated from the local wall $P_{x}$ near exit in Fig. $4(a)$ and the total pressure data, $P_{e x, 0}$ in Fig. 5(b), and is used with the data from Fig. 9. The difference between the calculated exit air bulk-mean temperature from Fig. 9 and $T_{m, x}$ from Eq. (4) is $3 \%$ for $R e=1670$ for the baseline case and $1 \%$ for $R e=3800$ with and without screen.

\section{SUMMARY And CONCLUSIONS}

The pressure drop, friction factors, and heat transfer are measured in a rectangular channel when a sinusoidal screen insert is employed as a turbulence promoter. The screen is a porous metal mesh available commercially. The period of the screen is $12.5 \mathrm{~mm}$ and peak-to-peak height of the screen is 5.0 $\mathrm{mm}$. The diamond shape pores in the screen provide a porosity of $79.4 \%$. The screen period is placed normal to the mean flow of the channel having the aspect ratio of 1:30.5. The Re for the measurements varies from 1360 to 3800 covering both the laminar and transition range of the flow. For the heat transfer measurements, the parallel walls of the channel touching the screen peaks are heated with constant heat flux to simulate the channels in a flat plate heat exchanger. Heat transfer measurements are also obtained with one heated wall with constant heat flux to simulate the single channel heat exchanger employed in solar heaters and electronic cooling. Baseline data in a smooth channel without the screen insert are also measured and compared with the data for the screen. The results on friction factors and heat transfer coefficients are then presented as the ratios of data from the screen channel to the smooth channel to provide the performance of the screen channel relative to the smooth channel. Data for the perforated plate-finned channel in literature are then also compared with the measured data. The results are summarized as follows.

(1) The total pressure drop across the screen channel and the temperature difference between the wall and exit air-stream from the screen channel suggest good turbulent mixing between the wall region and bulk flow in the screen channel. The resulting average uniform temperature and total pressure distributions along the channel height are one of the key operating objectives for employing inserts in the channels of the flat plate heat exchangers.

(2) The ratio $\left(f / f_{0}\right)$ increases with the $R e$ for $R e \leq 2700$ and reaches the maximum at $R e=2700$. At higher $R e$ in the transition flow regime, the $f / f_{0}$ ratio decreases slightly.

(3) However, the global ratio of $\left(\mathrm{Nu} / \mathrm{Nu} u_{0}\right)$ is the highest at higher transition $R e>3100$ when the $f / f_{0}$ decrease from the maximum. In the screen channel, fully developed $N u$ is 2.0-2.5 times of baseline $N u_{0}$ as the screen channel $f$ is 4.4 times of baseline $f_{0}$ at $3100<R e \leq 3800$.

(4) The flow is thermo-hydraulically fully developed near $X=0.38 \mathrm{~m}$ or $X / L=0.75$ in the screen channel for the range of $R e \leq 3800$.

(5) The local and global ratio of $\left(\mathrm{Nu} / \mathrm{Nu}_{0}\right)$ are always greater than 1.0 and increase with Re for both the cases of two heated walls and one heated wall. This suggests that for the same surface area 
and wall-to-mean flow temperature difference, the heat transfer is higher in the screen channel than in the baseline smooth channel. A flat plate heat exchanger with the screen insert will then have better thermal performance at the higher Re when the $f / f_{0}$ ratios decrease or change little.

(6) The performance index, $\left(\mathrm{Nu} / \mathrm{Nu} u_{0}\right) /\left(f / f_{0}\right)^{(1 / 3)}$ of the screen channel, which relates to the design objectives of reducing the heat transfer area and pumping power across the channel and enhancing the heat transfer rate to replace the smooth channel, is greater than 1.0 when the Re $>2500$ with both two heated walls and one heated wall. Relative to a smooth baseline channel, the design objectives are thus satisfied when the screen insert is employed in the same channel.

In conclusion, the commercial sinusoidal porous screen insert in the channels of a flat plate heat exchanger provides desirable effects on the heat transfer only for any operating range of the Reynolds number in transition range. However, when a higher thermal performance is desired that compensates for the increased pressure penalty due to the screen insert, the heat exchanger must operate at the higher transition Reynolds numbers. More study is needed to determine the effects of pore geometry, porosity, and wave period of the mesh screen on heat transfer and pressure drop in the channel.

\section{ACKNOWLEDGMENT}

The authors gratefully acknowledge the financial contributions of the NSERC Canada and Venmer CES (Saskatoon), Canada for the research. 


\section{NOMENCLATURE}

$\left(A, D_{h}\right) \quad$ channel cross-sectional area and hydraulic diameter, respectively

$C_{p} \quad$ constant pressure specific heat of air

$f \quad$ Darcy friction factor, $\left[(\Delta P / \Delta X) \cdot(H / 2) /\left(0.5 \cdot \rho_{a} \cdot V_{a}^{2}\right)\right]$

$(H, L, W)$ height, length, and width, respectively, of test section

$k_{a} \quad$ thermal conductivity of air

$M_{a} \quad$ air-mass flow rate

$\mathrm{Nu} \quad$ Nusselt number

$\left(P, P^{*}\right) \quad$ pressure and normalized pressure, respectively

$Q_{c} \quad$ convective power from a heated surface

Re flow Reynolds number, $\left[\left(M_{a} \cdot D_{h}\right) /\left(A \cdot \mu_{a}\right)\right]$

$\left(T, T^{*}\right) \quad$ temperature and normalized temperature, respectively

$V_{a} \quad$ mean flow velocity, $\left[M_{a} /\left(\rho_{a} \cdot A\right)\right]$

$(X, Y, Z) \quad$ Cartesian coordinate system

\section{Greek Symbols}

$\Delta \quad$ difference between two quantities

$\left(\rho_{a}, \mu_{a}\right) \quad$ air density and dynamic viscosity, respectively

\section{Subscripts}

0 reference value or local total pressure

a air property

(in, ex) inlet and exit of test section, respectively

$(m, w) \quad$ local bulk-mean temperature of air and local wall temperature, respectively 


\section{REFERENCES}

[1] Webb, R. L., and Kim, N-H, 2005, Principles of Enhanced Heat Transfer, second ed., Taylor and Francis, Oxon, UK, pp.57-60, 96-97, 127-128, 211-231, 246-269, 287-325.

[2] LePoudre, P. P., Simonson, C. J., and Besant, R. W., 2011, "Channel Flow with Sinusoidal Screen Insert," 19th Annual Conference of the CFD Society of Canada, 27-29 April 2011, Montreal, Canada.

[3] Fujii, M., Seshimo, Y., and Yamanaka, G., 1988, "Heat Transfer and Pressure Drop of Perforated Surface Heat Exchanger with Passage Enlargement and Contraction," Int. J. Heat Mass Transfer, 31(1), pp. 135-142.

[4] Torii, S., Yang, W., -J., and Umeda, S., 1999, "Flow Over a Slot-Perforated Flat Surface Between Two Parallel Plates," Int. J. Numerical Methods Heat Fluid Flow, 9(2), pp. 136-150.

[5] Varshney, L., and Saini, J. S., 1998, "Heat Transfer and Friction Factor Correlations for Rectangular Solar Air Heater Duct Packed with Wire Mesh Screen Matrices," Solar Energy, 62(4), pp. 255-262.

[6] Kiwan, S., and Al-Nimr, M. A., 2001, "Using Porous Fins for Heat Transfer Enhancement," J. Heat Transfer, 123, pp. 790-795.

[7] Hamdan, M., and Al-Nimr, M. A., 2010, "The Use of Porous Fins for Heat Transfer Augmentation in Parallel-Plate Channels," Transp. Porous Med., 84, pp. 409-420.

[8] Zhang, L. Z., and Chen, Z. Y., 2011, "Convective Heat Transfer in Cross-Corrugated Triangular Ducts Under Uniform Heat Flux Boundary Conditions," Int. J. Heat Mass Transfer, 54, pp. 597-605.

[9] Liang, C. Y., and Yang, W. J., 1975, "Heat Transfer and Friction Loss Performance of Perforated Heat Exchanger Surfaces," J. Heat Transfer, 97(1), pp. 9-15.

[10] International Standard, ISO 5167-1980(E), Measurement of Fluid Flow by Means of Orifice Plates, Nozzles and Venture Tubes Inserted in Circular Cross-Section Conduits Running Full, 1980-07-15.

[11] Available at: http://www.mmfilters.com/, accessed in December 04, 2011.

[12] Maranzana, G., Perry, I., and Maillet, D., 2004, "Mini- and Micro-Channels: Influence of Axial Conduction in the Walls," Int. J. Heat Mass Transfer 47, pp. 3993-4004.

[13] Beckwith, T. G., Marangoni, R. D., and Lienhard, J. H., 2007, Mechanical Measurements, sixth ed., Pearson Prentice Hall, New Jersey, pp. 42-45, 54-59.

[14] Moffat, R. J., 1988, "Describing the Uncertainties in Experimental Results," Exp. Thermal Fluid Sci., 1(1), pp. 3-17.

[15] Kline, S. J., and McClintock, F. A., 1953, "Describing Uncertainties in Single-Sample Experiments," Mech. Eng., 75, pp. 3.

[16] Panton, R. L., 1996, Incompressible Flow, second ed., J. Wiley and Sons Inc., USA, pp. 152-154.

[17] Ligrani, P. M., and Mahmood, G. I., 2003, "Spatially Resolved Heat Transfer and Friction Factors in a Rectangular Channel with 45-Deg Angled Crossed-Rib Turbulators," ASME J. Turbomachinery, 125, pp. 575-584.

[18] Kays, W. M., and London, A. L., 1964, Compact Heat Exchangers, second ed., McGraw-Hill, USA, pp. 155, 219.

[19] Shah, R. K., and London, A. L., 1978, Laminar Flow Forced Convection in Ducts-A Source Book for Compact Heat Exchanger Analytical Data, Academic Press Inc., New York, pp. 179-182, 305-308.

[20] Kays, W. M., and Crawford, M. E., 1993, Convective Heat and Mass Transfer, third ed., McGraw-Hill Inc., USA, pp. 348. 
[21] Gee, D. L., and Webb, R. L., 1980, "Forced Convection Heat Transfer in Helically Rib-Roughened Tubes," Int. J. Heat Mass Transfer, 23, pp. 1127-1136.

[22] Webb, R. L., and Eckert, E. R. G., 1972, "Application of Rough Surfaces to Heat Exchanger Design," Int. J. Heat Mass Transfer, 15, pp. 1647-1658.

[23] Angirasa, D., 2002, "Forced Convective Heat Transfer in Metallic Fibrous Materials," ASME J. Heat Transfer, 124, pp. 739-745. 


\section{Figure Captions List}

Fig. 1 (a) Schematic of test stand elevation view, (b) Test section geometry, and (c) Test section wall heater arrangement (drawn not to scale).

Fig. 2 (a) Plane view of thermocouple tip locations along test plate (dimensions in $\mathrm{mm}$ ) and (b) Elevation view of thermocouple tip locations in test plate.

Fig. 3 (a) Image of the actual sinusoidal air-filter screen and schematic of the screen sinusoid in YZ-plane (X: mean flow direction), and (b) Approximate geometry of screen mesh (dimensions in $\mathrm{mm}$ ) and Screen placement in test channel.

Fig. 4 (a) Normalized wall static pressure drop along test section with and without screen versus normalized distance, and (b) friction factor ratio versus Reynolds number.

Fig. 5 (a) Contours of normalized local total pressure, $\Delta P_{0}^{*}$ at $R e=1670$ and (b) pitchaveraged normalized total pressure, $\Delta P_{0}^{*}$ along height $(Z / H)$ in exit plane $(X / L=1.02)$ of screen test section.

Fig. 6 Nusselt numbers for two heated walls: (a)-(b) local $N u$ and $N u / N u_{0}$ along $X / L$, (c) streamwise-averaged $\mathrm{Nu} / \mathrm{Nu}$ along $\mathrm{Y} / \mathrm{W}$, and (d)-(f) globally-averaged $\mathrm{Nu}$ and $\mathrm{Nu} / \mathrm{Nu} \mathrm{u}_{0}$ as dependent upon $\mathrm{Re}$ and $f / f_{0}(\operatorname{Re}=1360-3800)$.

Fig. 7 Nusselt numbers for one wall heated: (a)-(b) local $N u$ and $N u / N u_{0}$ along $X / L$, (c) streamwise-averaged $\mathrm{Nu} / \mathrm{Nu}$ along $\mathrm{Y} / \mathrm{W}$, and (d)-(f) globally-averaged $\mathrm{Nu}$ and $\mathrm{Nu} / \mathrm{Nu} \mathrm{u}_{0}$ as dependent upon $\mathrm{Re}$ and $f / f_{0}(R e=1360-3800)$.

Fig. 8 The performance index: (a) $\left(\mathrm{Nu} / \mathrm{Nu} u_{0}\right) /\left(f / f_{0}\right)^{(1 / 3)}$ and (b) $\left(\mathrm{Nu} / \mathrm{Nu} \mathrm{u}_{0}\right) /\left(\mathrm{f} / \mathrm{f}_{0}\right)$ of the screen test section as dependent upon Re for two heated walls and one heated wall.

Fig. 9 Pitch-averaged normalized air temperature, $\Delta T_{a}^{*}$ along height $(Z / H)$ at exit plane of screen test section with two walls heated. 
Table Captions List

Table $1 \quad$ Test conditions 
Table 1. Test conditions

\begin{tabular}{|c|c|c|c|c|c|}
\hline$V_{a}(\mathrm{~m} / \mathrm{s})$ & $\operatorname{Re}=\left[\left(M_{a} \cdot D_{h}\right) /\left(A \cdot \mu_{a}\right)\right]$ & Heat flux $\left(\mathrm{W} / \mathrm{m}^{2}\right)$ & $C_{p}(\mathrm{~J} / \mathrm{kg} . \mathrm{K})$ & $\rho_{a}\left(\mathrm{~kg} / \mathrm{m}^{3}\right)$ & $T_{a, \text { in }}\left({ }^{\circ} \mathrm{C}\right)$ \\
\hline $2.1-6.0$ & $1360-3800$ & $184-575$ & 1005 & 1.131 & 23.3 \\
\hline
\end{tabular}




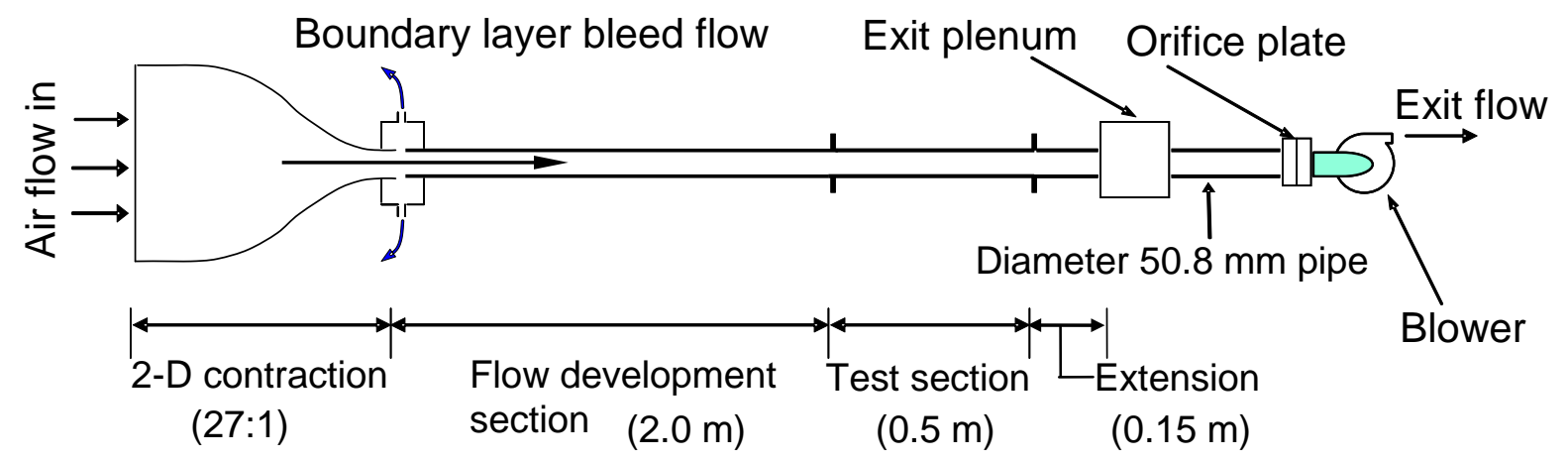

(a)

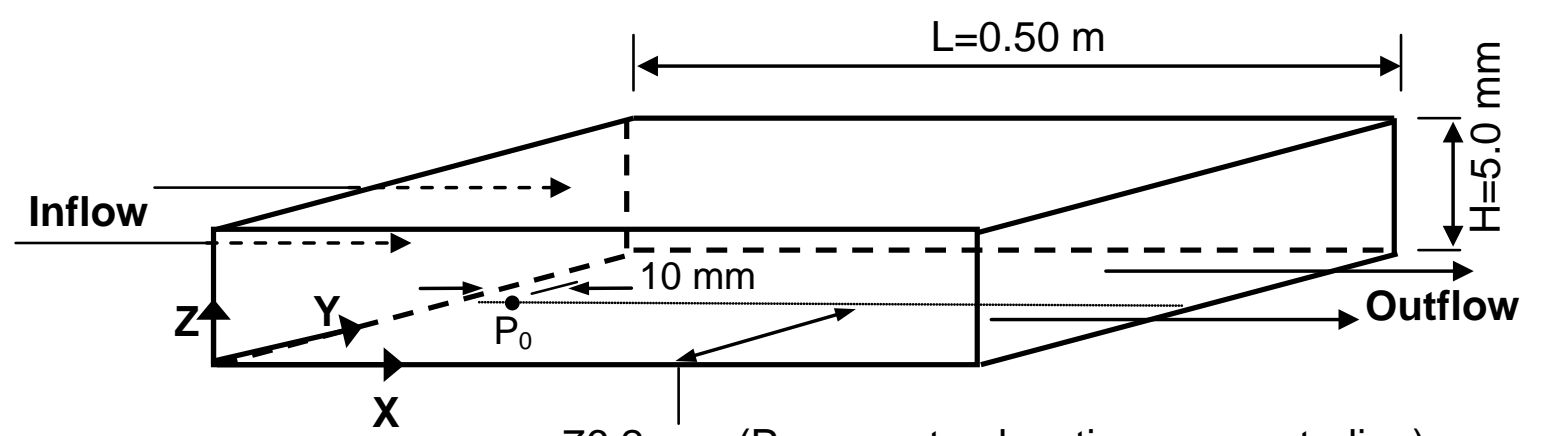

$76.2 \mathrm{~mm}$ (Pressure tap locations on centerline)

(b)

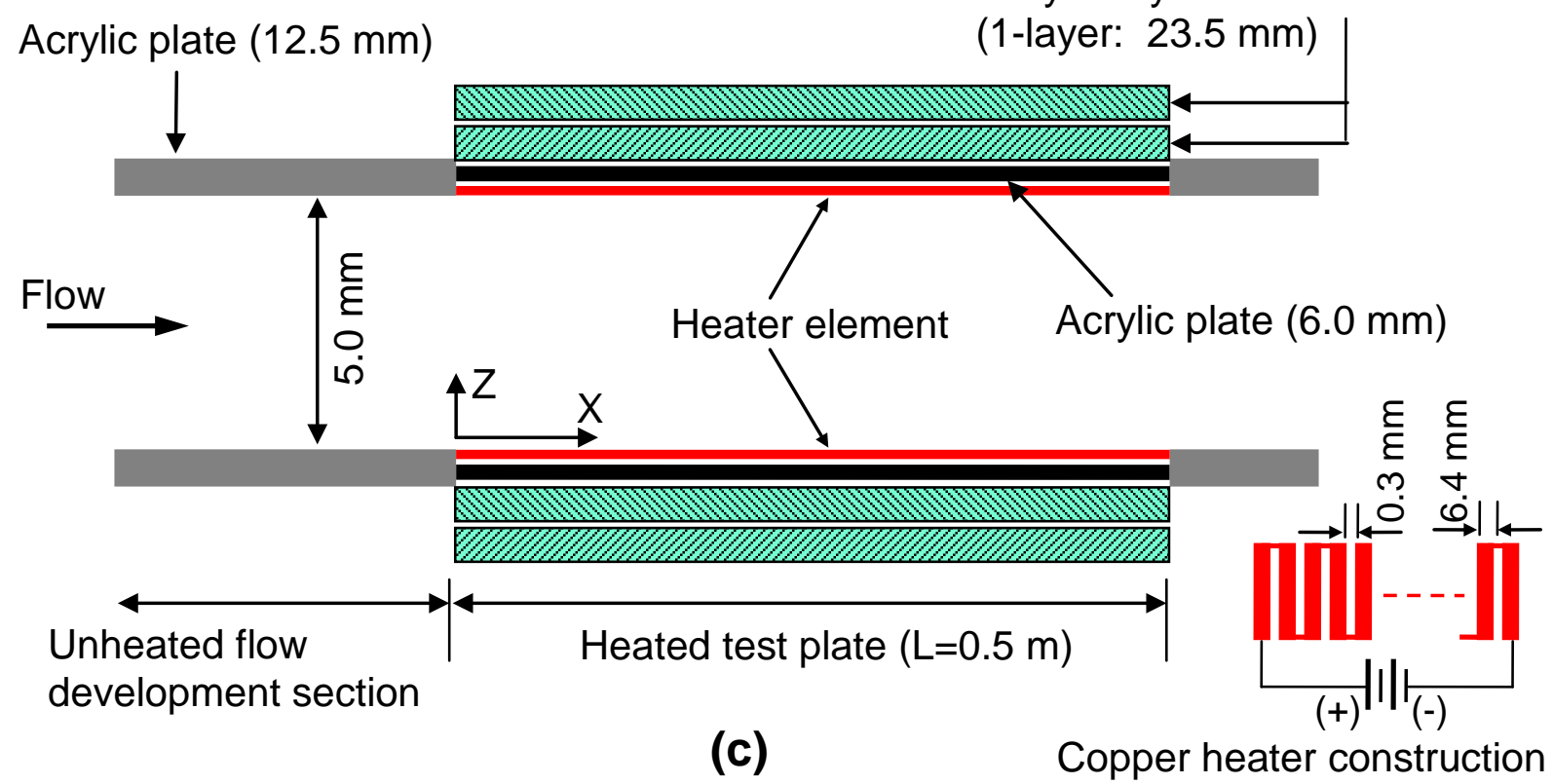

Fig. 1 (a) Schematic of test stand elevation view, (b) Test section geometry, and (c) Test section wall heater arrangement (drawn not to scale). 


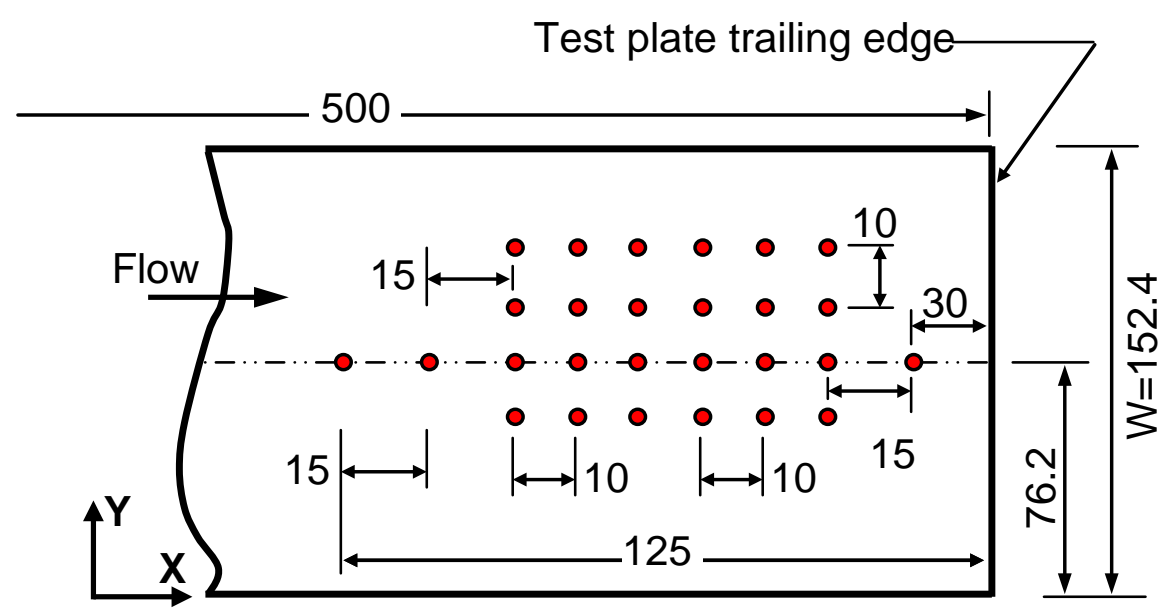

(a)

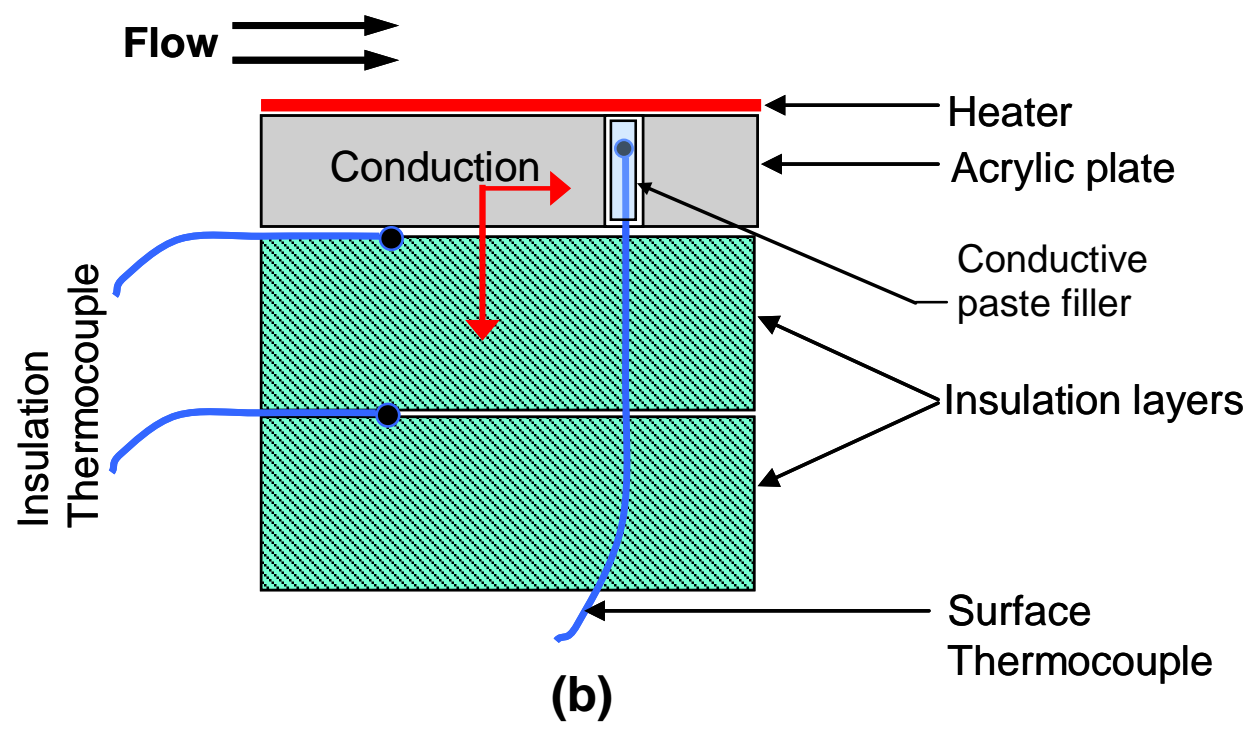

Fig. 2 (a) Plane view of thermocouple tip locations along test plate (dimensions in $\mathrm{mm}$ ) and (b) Elevation view of thermocouple tip locations in test plate. 


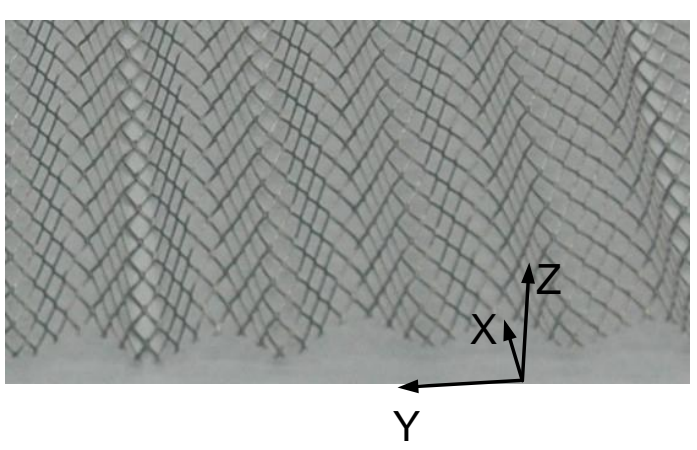

Screen photo in plane view

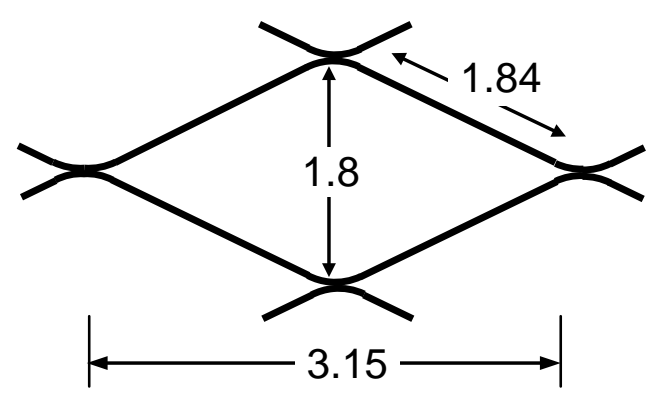

Screen mesh geometry

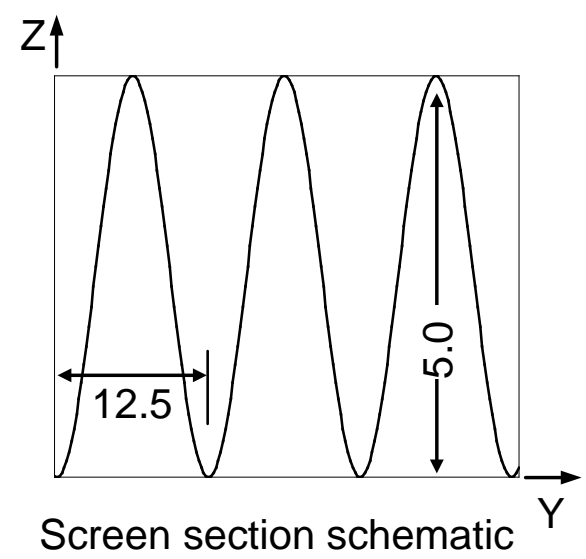

(a)

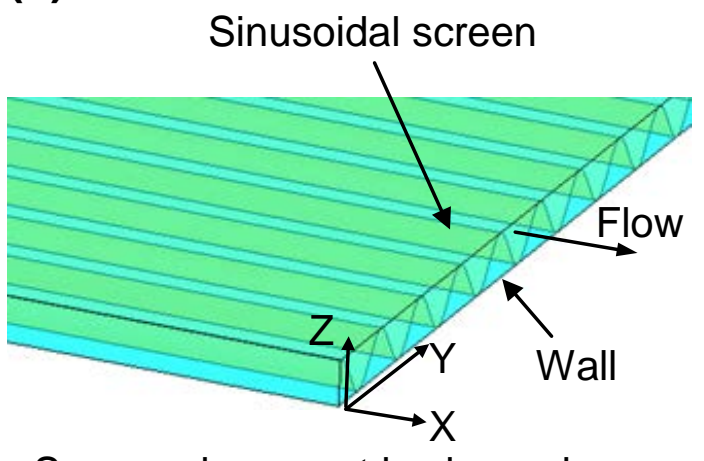

Screen placement in channel

Fig. 3 (a) Image of the actual sinusoidal air-filter screen and schematic of the screen sinusoid in YZ-plane ( $\mathrm{X}$ : mean flow direction), and (b) Approximate geometry of screen mesh (dimensions in $\mathrm{mm}$ ) and Screen placement in test channel. 


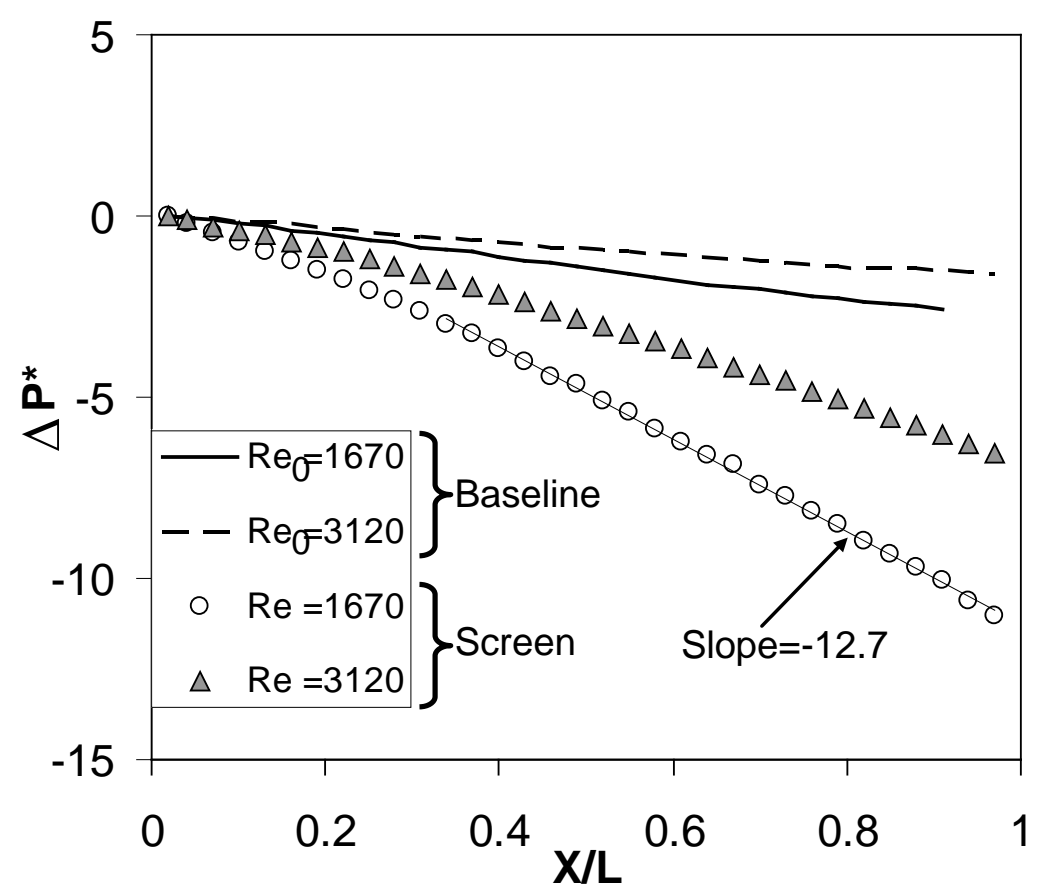

(a)

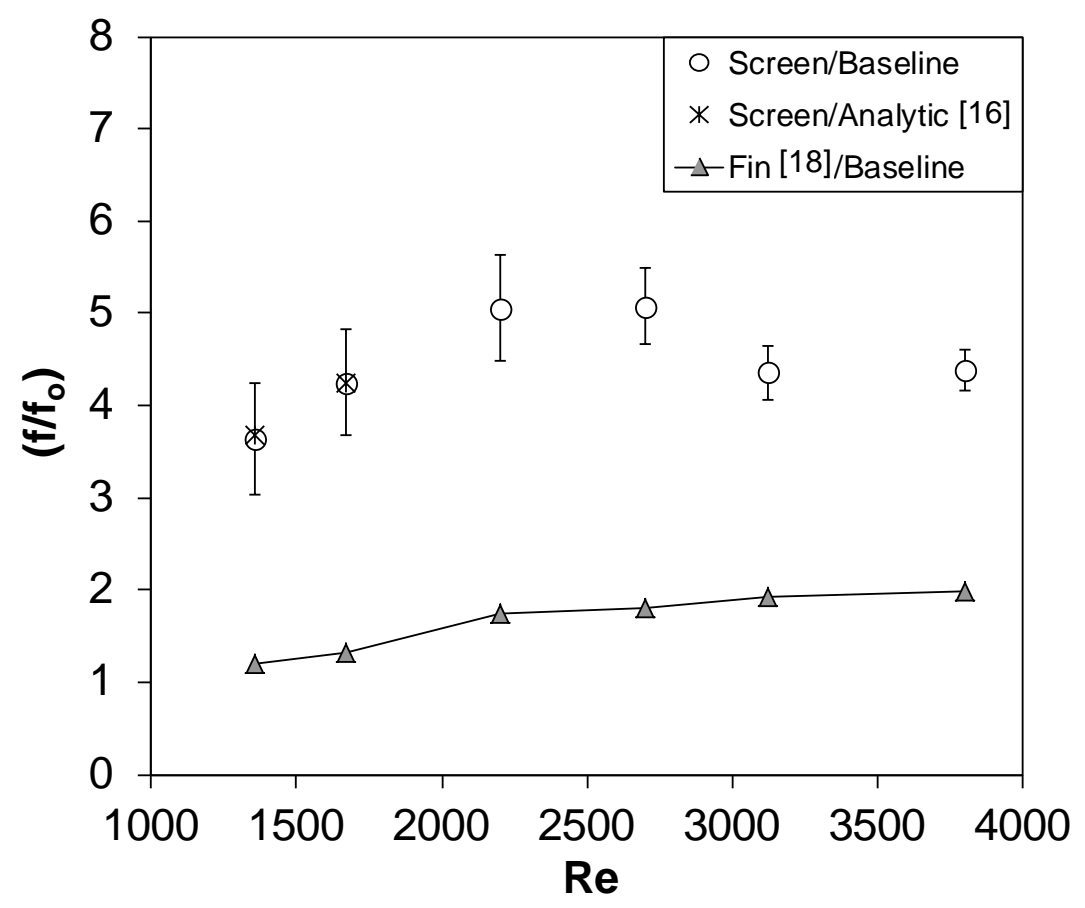

(b)

Fig. 4 (a) Normalized wall static pressure drop along test section with and without screen versus normalized distance, and (b) friction factor ratio versus Reynolds number. 


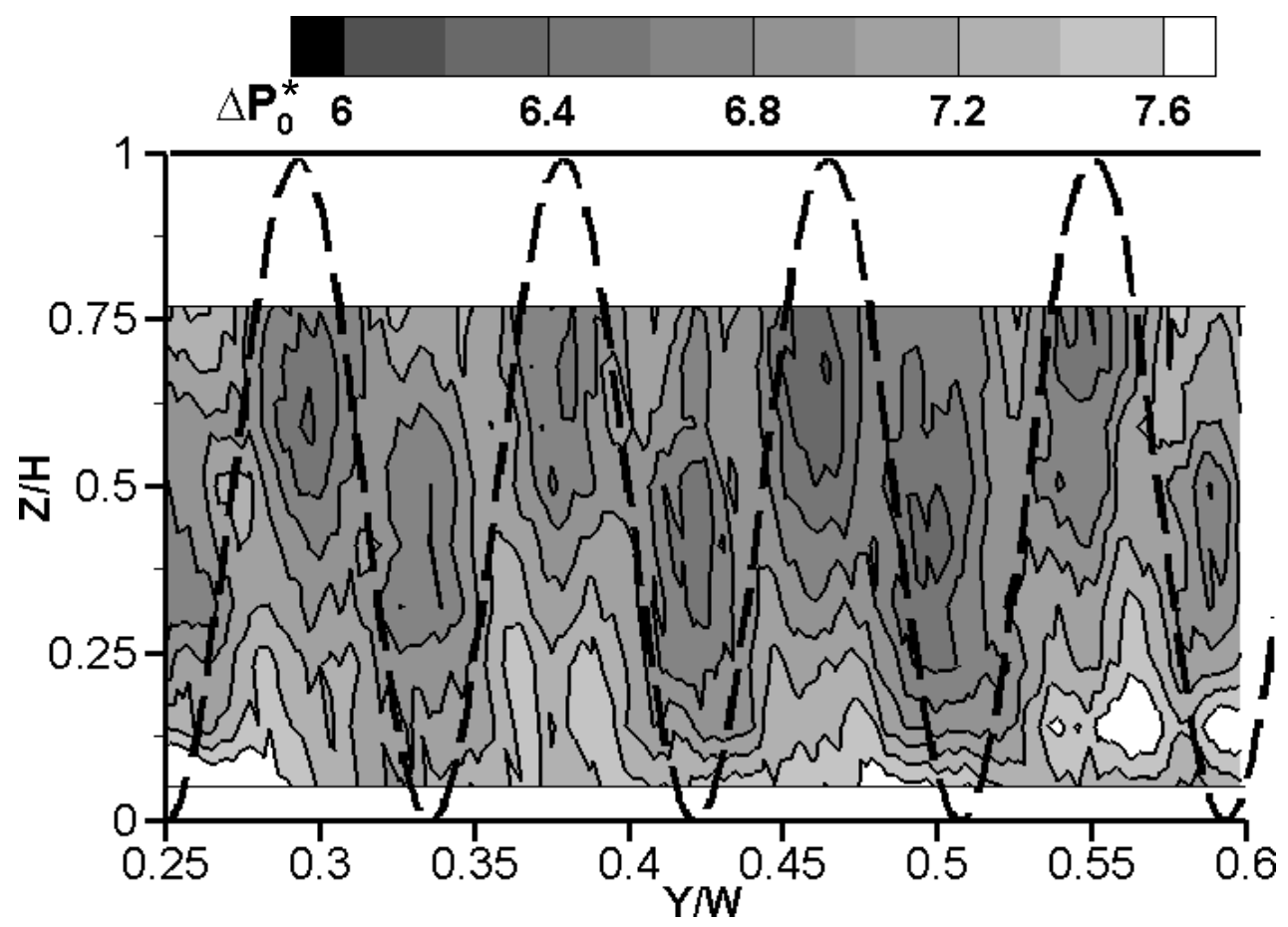

(a)

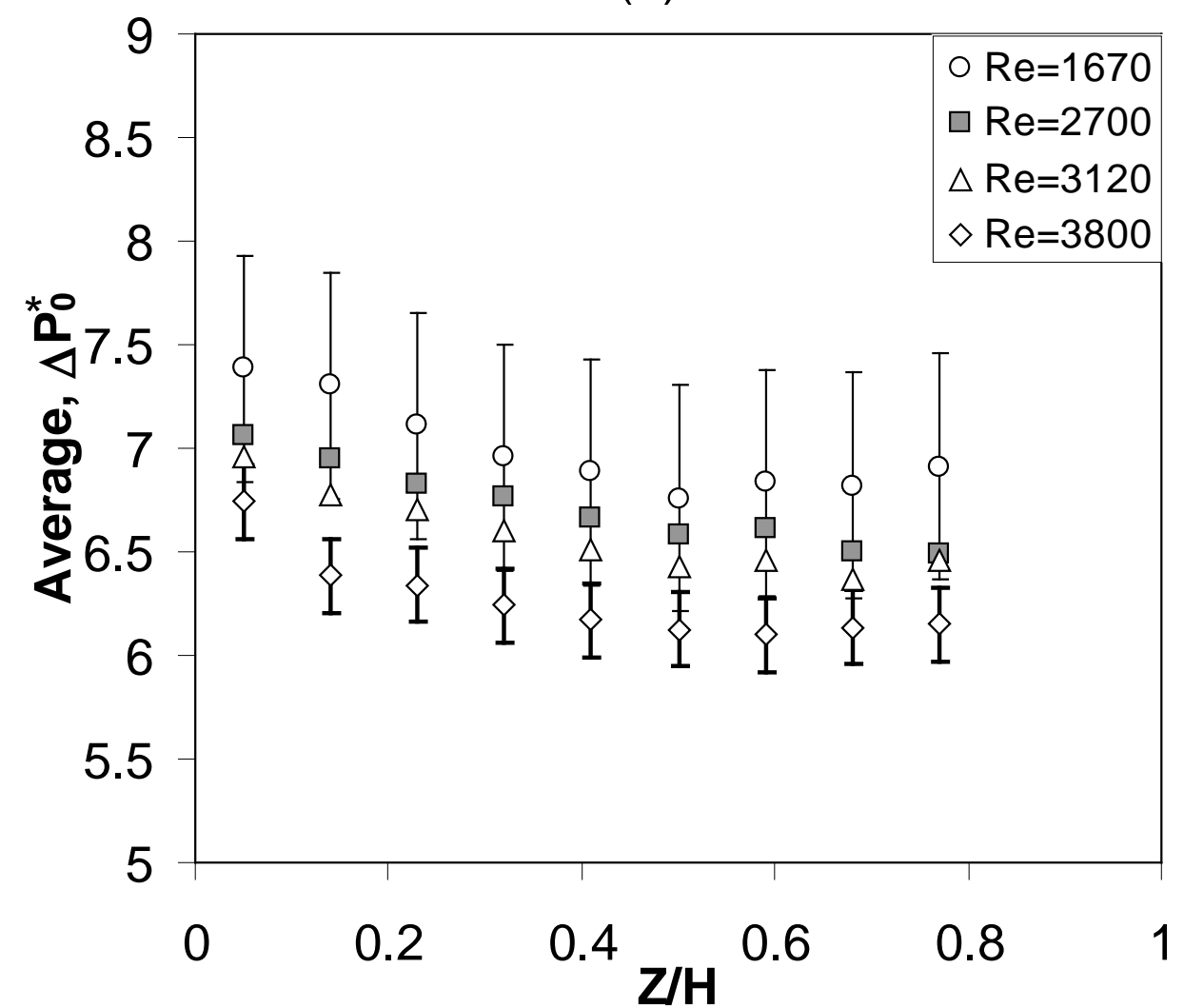

(b)

Fig. 5 (a) Contours of normalized local total pressure, $\Delta P_{0}^{*}$ at $R e=1670$ and (b) pitch-averaged normalized total pressure, $\Delta P_{0}^{*}$ along height $(Z / H)$ in exit plane $(X / L=1.02)$ of screen test section. 

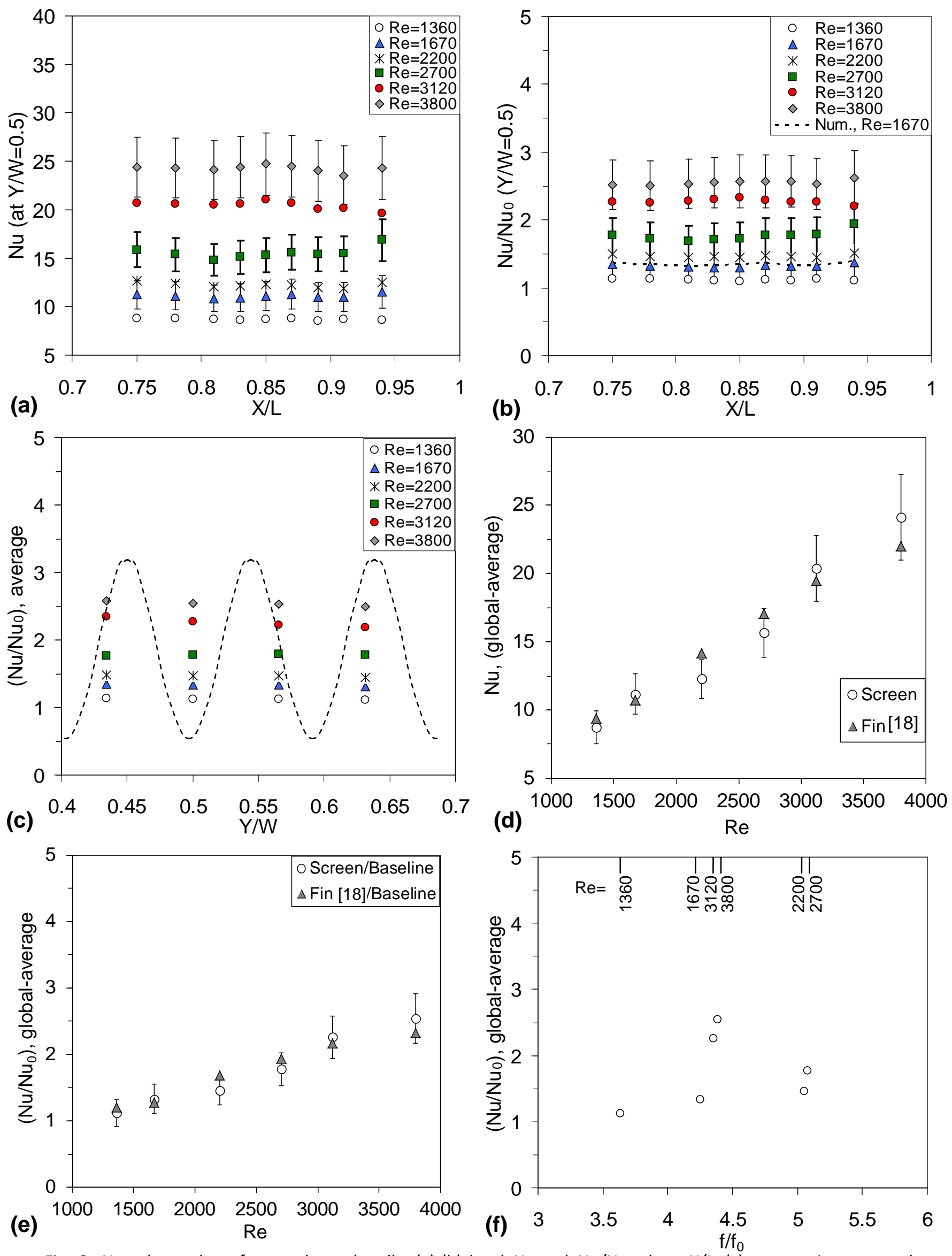

Fig. 6 Nusselt numbers for two heated walls: (a)-(b) local $N u$ and $N u / N u_{0}$ along $X / L$, (c) streamwise-averaged $\mathrm{Nu} / \mathrm{Nu} u_{0}$ along $\mathrm{Y} / \mathrm{W}$, and (d)-(f) globally-averaged $\mathrm{Nu}$ and $\mathrm{Nu} / N u_{0}$ as dependent upon $\operatorname{Re}$ and $f / f_{0}(\operatorname{Re}=1360-3800)$. 

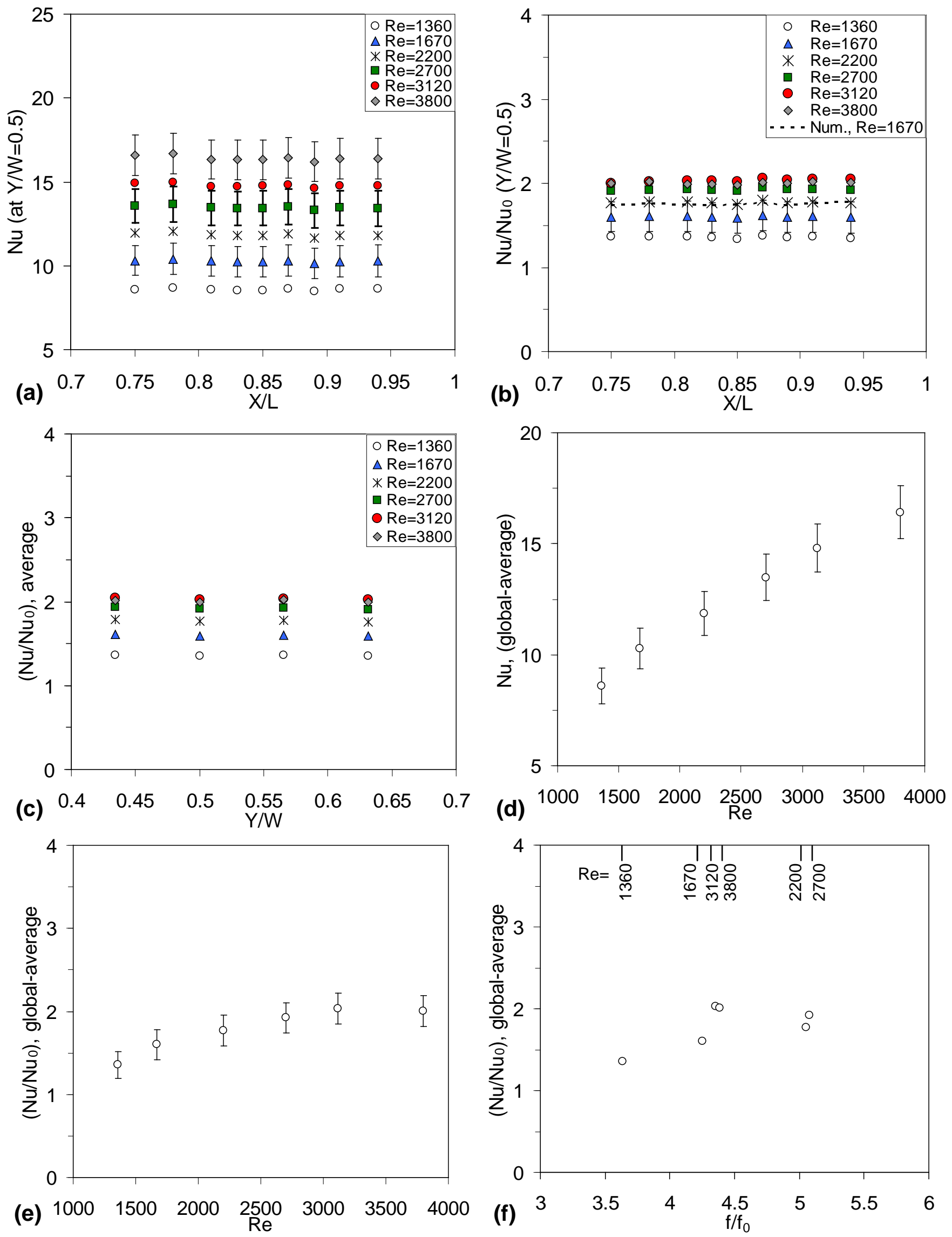

Fig. 7 Nusselt numbers for one wall heated: (a)-(b) local $\mathrm{Nu}$ and $\mathrm{Nu} / \mathrm{Nu} u_{0}$ along $X / L$, (c) streamwise-averaged $\mathrm{Nu} / \mathrm{Nu} u_{0}$ along $\mathrm{Y} / \mathrm{W}$, and (d)-(f) globally-averaged $\mathrm{Nu}$ and $\mathrm{Nu} / \mathrm{Nu} u_{0}$ as dependent upon $R e$ and $f / f_{0}(R e=1360-3800)$. 


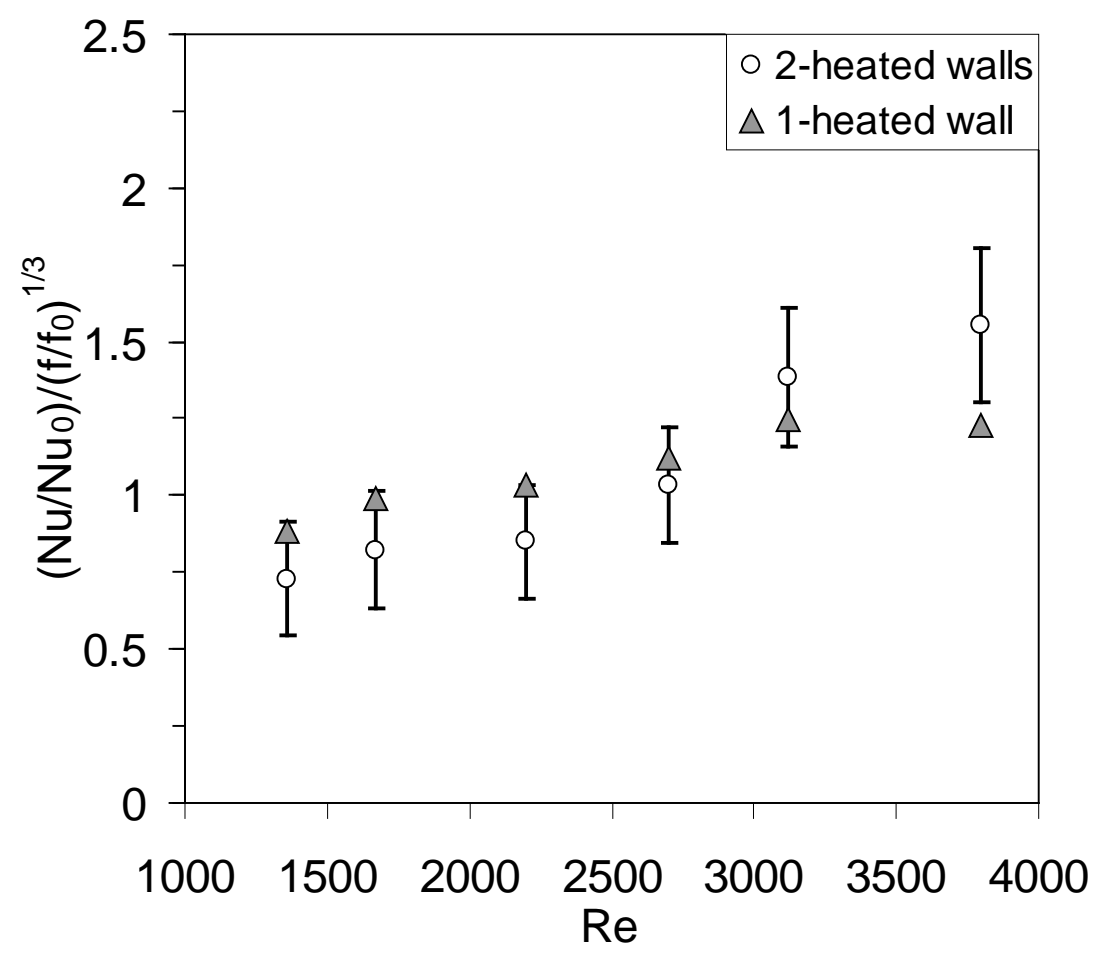

(a)

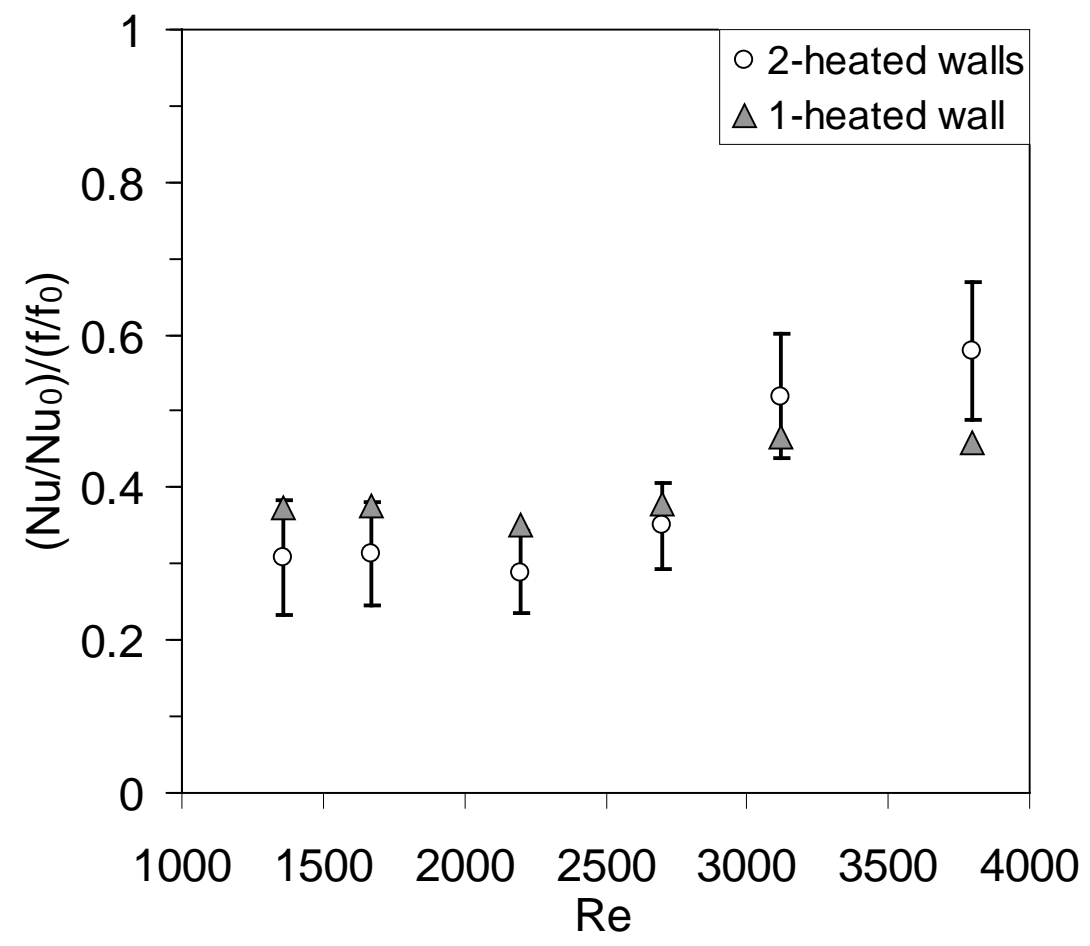

(b)

Fig. 8 The performance index: (a) $\left(\mathrm{Nu} / \mathrm{Nu} u_{0}\right) /\left(f / f_{0}\right)^{(1 / 3)}$ and (b) $\left(\mathrm{Nu} / \mathrm{Nu} u_{0}\right) /\left(f / f_{0}\right)$ of the screen test section as dependent upon $R e$ for two heated walls and one heated wall. 


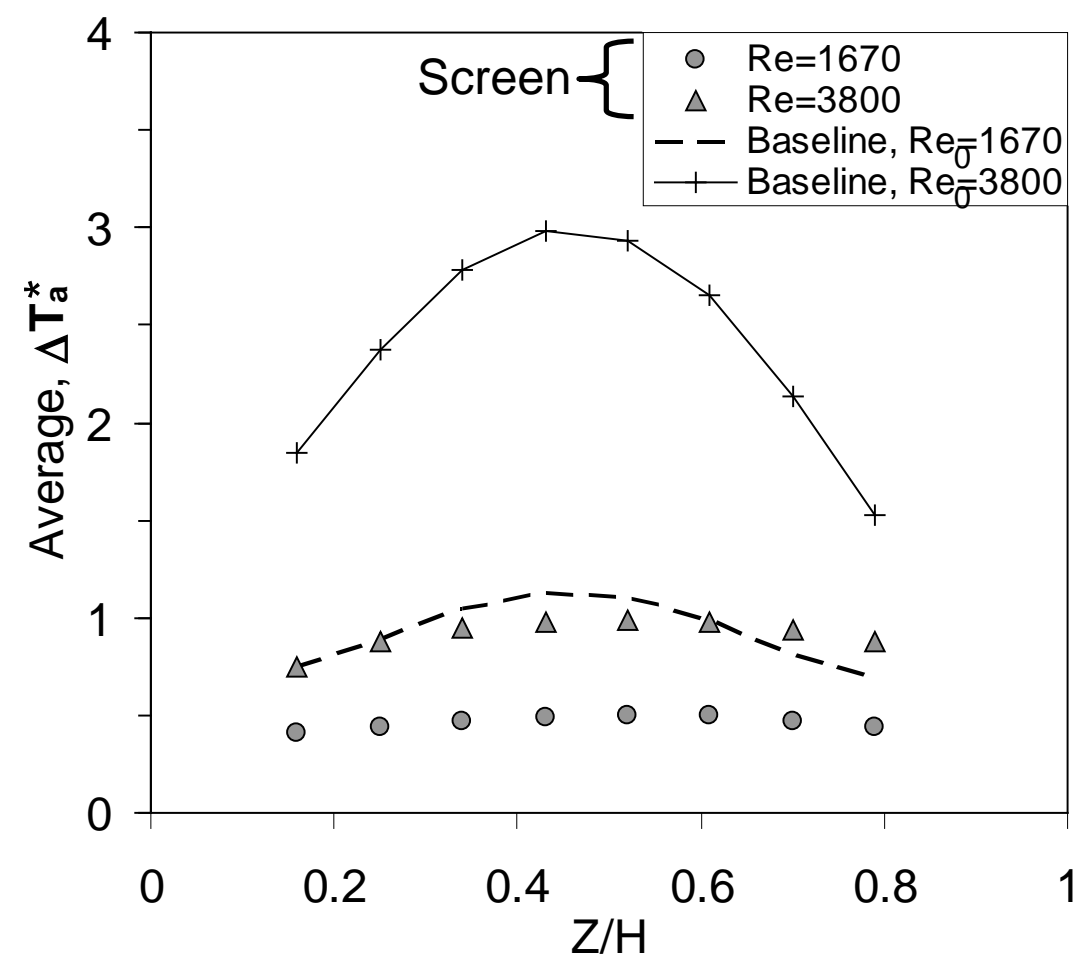

Fig. 9 Pitch-averaged normalized air temperature, $\Delta T_{a}^{*}$ along height $(Z / H)$ at exit plane of screen test section with two walls heated. 